\title{
Assessing the Risk of Ship Hull Collapse due to Collision
}

\author{
Samy A.M. Youssef ${ }^{1,2}$, Muhammad Faisal ${ }^{1}$, Jung Kwan $\mathrm{Seo}^{1}$, Bong Ju Kim${ }^{1}$, Yeon Chul Ha ${ }^{1}$, Do Kyun $\mathrm{Kim}^{3}$, Jeom \\ Kee Paik ${ }^{1 *}$, Fai Cheng ${ }^{4}$ and Min Soo Kim ${ }^{4}$ \\ ${ }^{I}$ The Korea Ship and Offshore Research Institute (The Lloyd's Register Foundation Research Centre of Excellence), \\ Pusan National University, Busan, Korea \\ ${ }^{2}$ Marine Engineering Technology Department, Arab Academy for Science, Technology and Maritime Transport, \\ AbuQir, Alexandria, Egypt \\ ${ }^{3}$ Department of Civil Engineering, University Teknologi PETRONAS, Tronoh, Perak, Malaysia \\ ${ }^{3}$ Lloyd's Register, Southampton, UK
}

*Corresponding author: J.K. Paik, jeompaik@pusan.ac.kr

\begin{abstract}
This study proposes a method for assessing the risk of ship hull collapse following a collision. A probabilistic approach is applied to establish the relationship between the exceedance probability of collision versus the residual ultimate strength index. A set of credible collision scenarios which represent the entire range of possible collision accidents is selected using a sampling technique based on probability density distributions of influencing parameters. The amount and location of collision damage for selected individual collision scenarios are characterised using the LS-DYNA nonlinear finite element method. The ultimate hull girder strength of a ship with predefined collision damage is then calculated using the ALPS/HULL intelligent supersize finite element method. To demonstrate the applicability of the proposed method, applied examples are given, involving collisions with a hypothetical Suezmaxclass double-hull oil tanker. Based on the results, design formulations for predicting the residual strength index of damaged ship hulls are derived in an empirical manner. The examples show that the proposed method will be very useful for evaluating the risk of collapse of a ship's hull after sustaining collision damage, which may contribute to a collision risk-based design (RBD) framework. Moreover, the method will be useful in rescue and salvage operations immediately after a collision by permitting a rapid assessment of the structural safety of a damaged ship.
\end{abstract}

Keywords; Risk assessment, Structural safety, Hull collapse, Collision accident, Probabilistic approach, Exceedance diagrams.

\section{Introduction}

The collapse of a ship hull girder is considered to be one of the most catastrophic failure events, especially if the ship is already damaged from an accident such as collision or grounding (i.e. post-accident collapse). A damaged ship can lose hull girder strength partially or totally (depending on the damage characteristics), and the hull girder strength may then be insufficient to sustain the required loads. This can occur not only directly after the accident but also during salvage operations or while being towed to the nearest repair yard. This type of structural failure 
following an accident may have serious consequences such as loss of life, environmental damage and economic loss, especially if large tankers or liquefied natural gas (LNG) and/or nuclear-powered vessels are involved. It is thus of paramount importance to accurately and efficiently assess the risk of ship hull collapse after collision damage is sustained to determine whether the damaged hull will remain within an acceptable safety range.

Over the past decades, several studies have assessed the performance of damaged ships after collision and grounding events. Most of these studies focused mainly on prescriptive approaches for evaluating the structural safety of damaged ships (Paik et al., 1998; Wang et al., 2002; Qi and Cui, 2006; Khan and Das, 2008; Hussein and Soares, 2009). To identify collision scenarios and their consequences using traditional prescriptive approaches, one or more severe accidental scenarios that would have the most unfavourable consequences (i.e. the worst cases), were considered. Information from classification society rules (e.g. ABS, 1995; DNV, 2009) were also used to deterministically define the collision damage scenarios. In addition, some studies identified more realistic collision damage characteristics by performing large-scale ship-ship collision analyses (Servis et al., 2002; Ozguc et al., 2005; Sun et al., 2011). According to the literature, the residual ultimate strength of damaged hulls can be predicted using several methods, classified as analytical methods (Smith, 1977), nonlinear finite element methods (Chen et al., 1983), the idealized structural unit method (ISUM) (Ueda et al., 1984; Paik et al., 1996), and the intelligent supersize finite element method (ISFEM) (Hughes and Paik, 2013; Magona and Flockhart, 2014).

In the traditional deterministic procedure for assessment of safety, the structural safety of a damaged ship is evaluated by comparing the residual ultimate strength of the hull girders with applied extreme hull girder loads to ensure a safety margin or redundancy of the structure following collision damage. For example, Paik et al. (1998) developed a procedure for assessing the possibility of hull girder collapse in a damaged condition, based on a prescriptive approach.

Prescriptive solutions are, however, often insufficient for innovation because they can result in unfavourable design loads and may not address all possible accidental circumstances. The nature of ship collision is rather uncertain and probabilistic, involving a variety of influencing parameters that are naturally probabilistic, and the use of probabilistic approaches is therefore desirable.

In probabilistic risk-based approaches, a number of relevant collision scenarios are described by influencing parameters that are treated as random variables. The selected scenarios are as close as possible to actual situations. The probability of collision occurrence is estimated, to represent the probability level for each scenario. Using methods already available, the residual ultimate strength of the hull girders can be calculated. A probabilistic risk analysis can be carried out by associating the collision probability analysis with the residual ultimate strength calculations. Based on this approach, structural safety can be measured by predicting the risk level for ship hull collapse following damage and comparing it with an acceptable level. Figure 1 shows a brief comparison between the traditional prescriptive approach and the risk-based approach.

The objectives of the present study are to develop an efficient probabilistic approach for assessing the risk of ship hull collapse following a collision. A set of credible ship-ship collision scenarios is selected using a sampling 
technique in which the probability density distributions of the influencing parameters are characterised in a probabilistic manner. The collision damage for individual collision scenarios is identified using the ALPS/HULL (ALPS/HULL, 2012) intelligent supersize finite element method. A relationship is established between the exceedance probability of collision versus the residual ultimate hull girder strength index, which can be used to determine the risk of ship hull collapse following a collision. More details about the procedures of the proposed method are given in the following section.
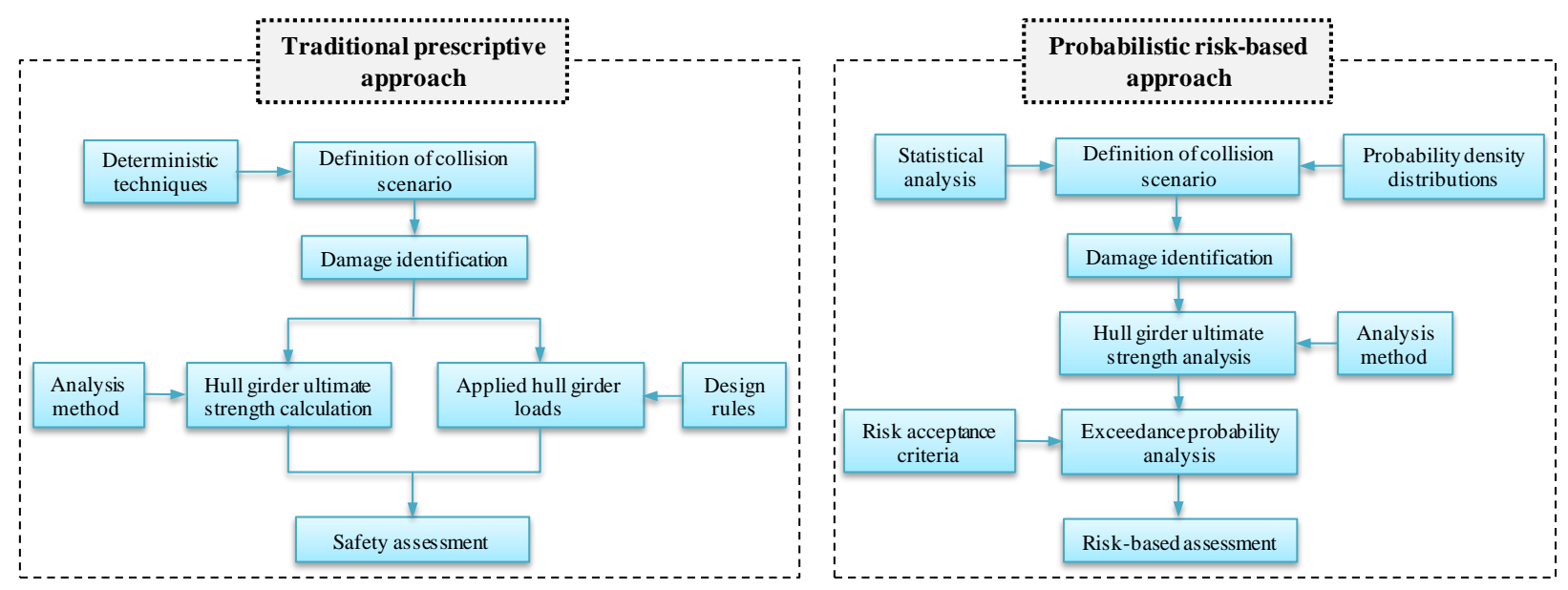

Fig. 1 Traditional prescriptive approach versus probabilistic risk-based approach.

\section{General Procedures for the Proposed Method}

Figure 2 shows a detailed outline of the procedure used in the proposed method, starting with identification of the target structure's structural topology and ending with assessment of the risk of hull collapse of the target ship following a collision. 


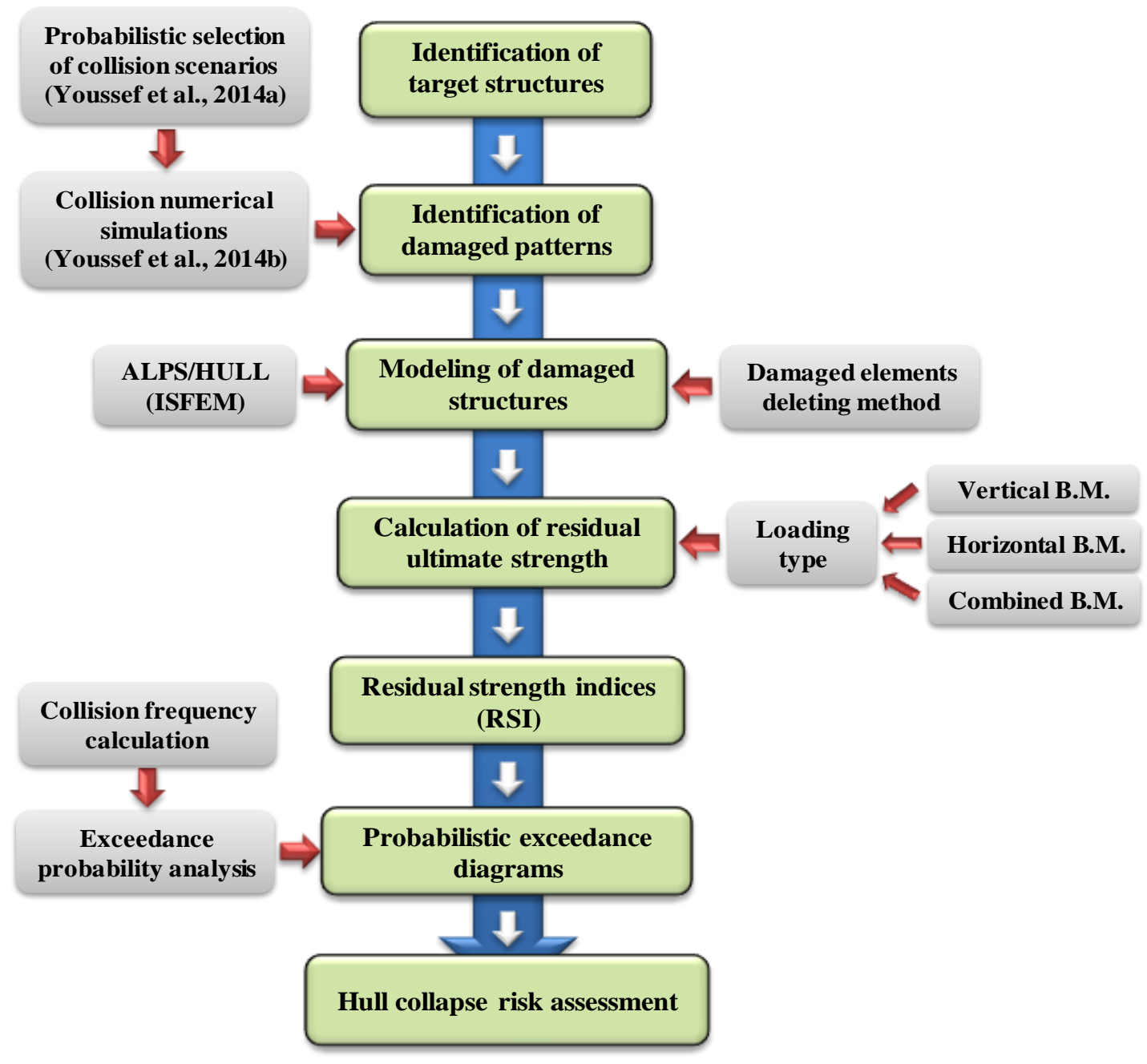

Fig. 2 Procedures of the proposed method.

[In the third green box of the figure, please change 'Modeling' to 'Modelling'.]

In this study, the probabilistic method introduced by Youssef et al. (2014b) is employed to define a relevant set of ship-ship collision scenarios that can be considered to be a representative sample of all possible scenarios. More details about this method are given in Section 3.2.

To predict more realistic collision damage characteristics, collision numerical simulations for the selected scenarios are carried out using nonlinear finite element methods (Youssef et al., 2014a). Based on the results obtained, damage characteristics are identified in terms of the location and extent of structural damage in the directions of the ship's length, breadth and depth.

When a ship's structure is damaged through an accident, the damaged structural elements may not make any contribution towards global ship strength. The damaged elements should thus be eliminated from strength calculations by being removed from the relevant part of the ship's cross-section. This method, called the 'damaged element removal method', has been used in several related studies. 
Taking computational cost into consideration, ALPS/HULL (2012) is used in modelling and calculating the ultimate longitudinal strength for both intact and damaged structures. Various loading types can be applied to the target ship's hull cross-section: pure vertical and pure horizontal bending moments, and a combination of these.

The reduction in the strength capacity of the damaged ship's hull structure is presented in terms of the residual strength index (RSI), which is based on the ultimate longitudinal hull girder strength (i.e. the ultimate bending moment of the damaged hull is compared with that of the intact one). Equation (1) defines the $\mathrm{RSI}_{i}$ for the damaged and intact cross-sections of the $i$ th accidental scenario, where $M_{\mathrm{I}_{-} i}$ and $M_{\mathrm{D}_{-} i}$ are the ultimate bending moments for the intact and the damaged hull cross-sections, respectively.

$$
R S I_{i}=\frac{M_{D_{-} i}}{M_{I_{-} i}}
$$

Following the probabilistic approach, a collision probability analysis is carried out for each collision scenario (Youssef et al., 2014a). A probability of exceedance analysis is then performed to establish the relationship between the exceedance probability of collision and the residual ultimate strength index (RSI), in the form of exceedance diagrams. After these procedures are completed, the risk of collapse of the damaged hull can be readily evaluated. A damaged ship may be subject to heeling due to outflow of the cargo and/or inflow of seawater through an opening in the hull. The effect of heeling can also be considered in the proposed method.

\section{Applied Examples}

In this section, the proposed method is applied to a hypothetical ship structure. A limited number of collision scenarios are selected and the probability of occurrence calculated for each, but it can represent an entire range of collision accidents. The collision damage is identified and numerically modelled using finite element tools. Taking a vertical bending load as the worst load case, the first example predicts the target ship's hull girder bending capacity under a vertical bending moment only. To give a more complete picture, the second example considers the combined effect of vertical and horizontal bending moments on the ship's hull girder strength.

In the present examples, the hull is assumed to be in an upright position (i.e. the heel angle is zero in all scenarios) even after the collision occurs. However, the assumption may be relevant if a fully laden oil tanker is involved, as the effect of flooding may be small due to the nature of the cargo carried, regardless of possible flooding into side ballast tanks.

\subsection{Target Structure}

A Suezmax-class double-hull oil tanker is used in the analysis as the ship struck in 30 ship-ship collision scenarios.

The ship is assumed to be in as-built structural condition, with as-built thicknesses and being free from any impairment. Table 1 gives the ship's principal dimensions. 
Table 1. Principal dimensions of a Suezmax-class double-hull oil tanker.

\begin{tabular}{ll}
\hline Item & Dimension \\
\hline Length overall (m) & 272.0 \\
Length between perpendiculars (m) & 264.0 \\
Moulded breadth (m) & 48.0 \\
Moulded depth (m) & 23.7 \\
Design draft (moulded) (m) & 16.0 \\
Deadweight (DWT) & 157,500 \\
Double side width (m) & 2.64 \\
Double bottom height (m) & 2.64 \\
Transverse frame spacing (m) & 4.8 \\
\hline
\end{tabular}

\subsection{Collision Scenario Selection}

Following the method developed by Youssef et al. (2014b), each collision scenario is defined according to the parameters that govern ship-ship collisions, such as ship mass, speed, draft, collision angle, impact location, bow shape of striking ship, etc. Each parameter is treated as a random variable with its own probability density distribution (PDF). As consideration of every possible scenario is not practical, a sampling technique was applied to randomly select 30 scenarios. The target ship is assumed to encounter different types of other ship. Complete details for the scenario selection procedure are given in Youssef et al. (2014b).

\subsection{Collision Frequency Analysis}

Ship collision and grounding frequency models have classically been based on the product of the causation probability and the geometrical probability (Fujii and Tanaka, 1970; Macduff, 1974). Causation probability is the probability of failing to avoid an accident while on a collision course, and the geometrical probability is the number of collision candidates if no avoidance measures are taken, i.e. by assuming that the navigator is blind (Pedersen, 1995). In the current calculations, Pedersen's model (Pedersen, 1995) is used to calculate the geometrical probability of a vessel encountering one of the collision scenarios. The collision frequency, in units of the number of accidents per ship-year, is calculated for each collision scenario as the product of the number of collision candidates and the related causation probability. Based on these calculations, the total collision frequency is 3.09 x $10^{-3}$ per ship-year. More details are available in Youssef et al., (2014a).

\subsection{Collision Numerical Analysis}

The large-scale collision simulations presented in Youssef et al. (2014a) are used in the present study; the finite element model and the simulation set-up are thus only described briefly in this section. A full-scale finite element model of the target ship described in Section 3.1 is established by considering the element type, mesh size, material model, and fracture criteria. Using the nonlinear finite element software LS-DYNA (Hallquist, 2010), the selected scenarios are simulated and analysed with calculations being carried out in the time domain using the explicit analysis method. The effect of the surrounding seawater is taken into consideration as a virtual added mass of the target ship in terms of surge, sway and yaw (Pedersen and Zhang, 1998; Sajdak and Brown, 2005). The rigid body 
motion relating to the external dynamics of the ships is calculated using 'MCOL' (Ferry et al., 2002), a subroutine within the LS-DYNA program. Figure 3 shows the set-up for collision scenario 15, which has the bow portion of a bulk carrier striking the target finite element model.

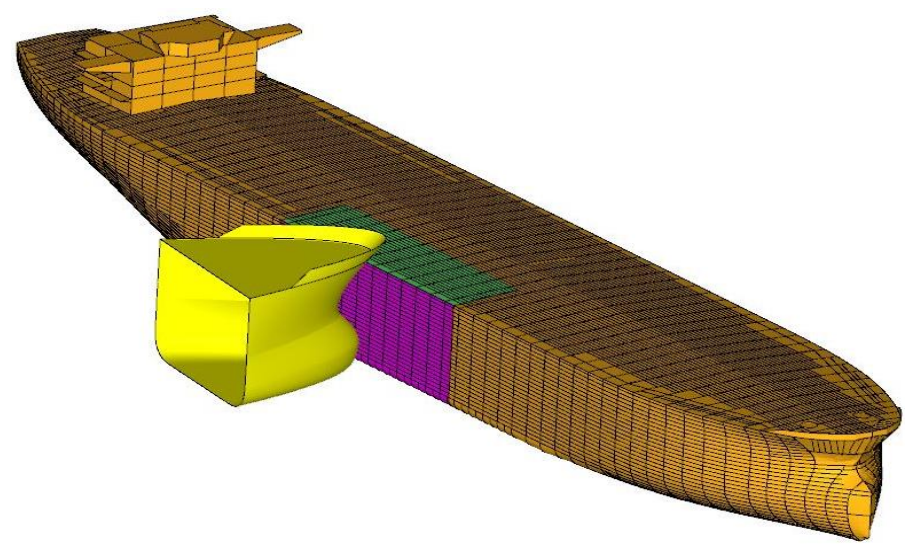

Fig. 3 Ship-ship collision finite element simulation.

\subsection{Damage Identification and Modelling}

Based on the numerical simulation results for the 30 ship-ship collision scenarios, damage is identified in terms of the location and extent of structural damage in the directions of the ship's length (due to different longitudinal impact locations), breadth and depth.

ALPS/HULL (2012) is used to model the target ship's hull cross-sections in both the intact and the damaged condition for each scenario. In the examples presented, any initial imperfection in the structural members is assumed to be slight and welding-induced residual stress is not taken into account. To model the damaged structures, each model is idealised in terms of the location and extent of damage in the directions of the ship's breadth and depth and the location of damage in the direction of its length; the extent of damage in the direction of the ship's length is not taken into account. The 'damaged element removal method' is then applied to model the hull damage in each case (see section 2).

Figures 4 and 5 show the ALPS/HULL intelligent supersize finite element models for the target Suezmax-class double-hull oil tanker in both the intact and the damaged condition (scenario 14), respectively. 


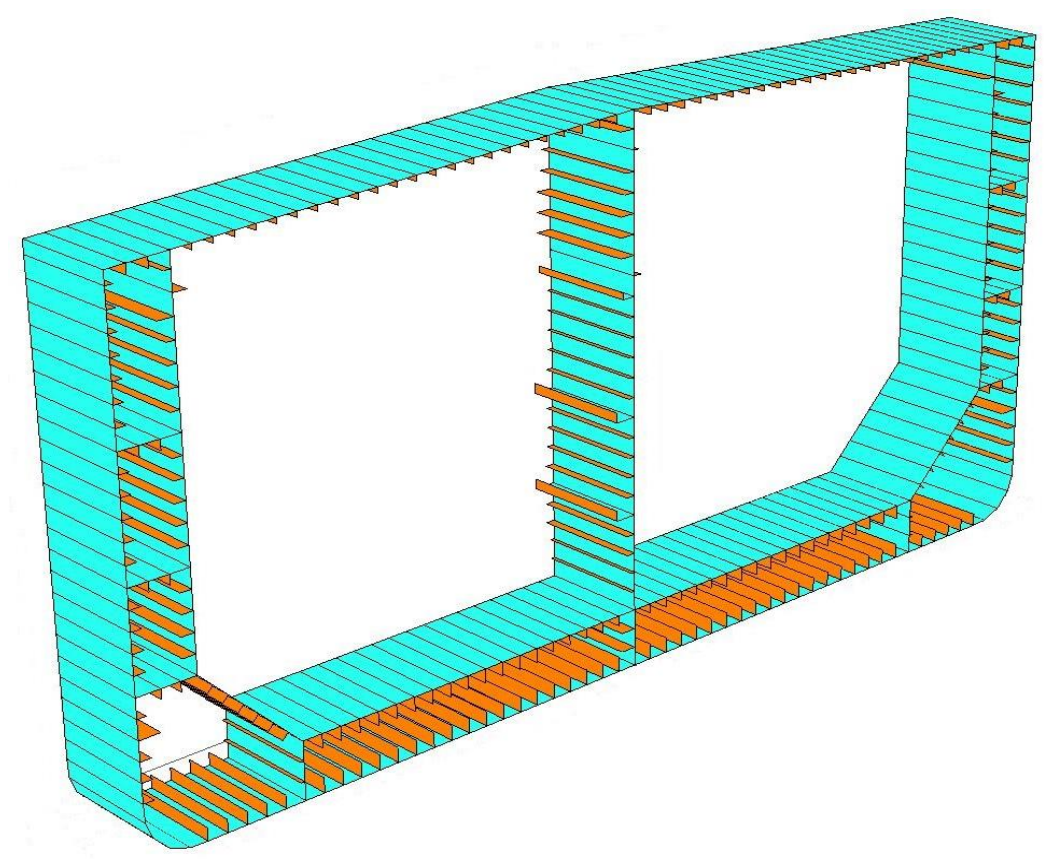

Fig. 4 ALPS/HULL intelligent supersize finite element model for the target Suezmax-class double-hull oil tanker in the intact condition.

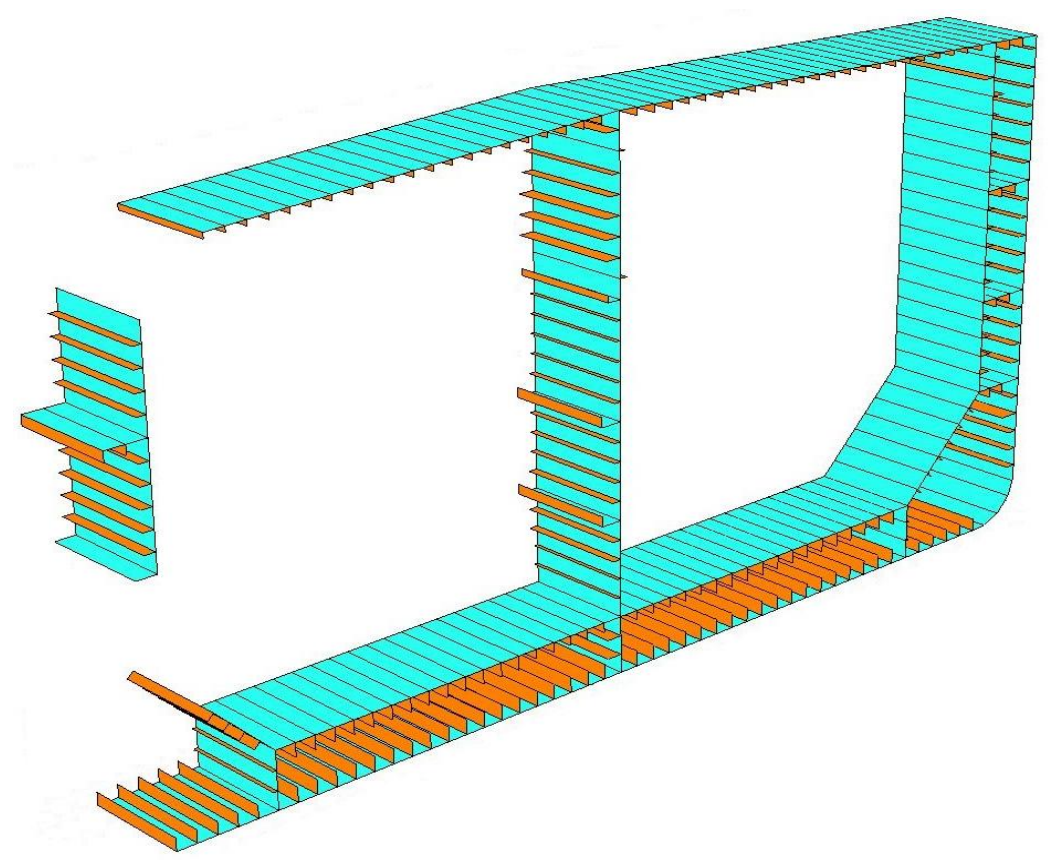

Fig. 5 ALPS/HULL intelligent supersize finite element model for the target Suezmax-class double-hull oil tanker in the damaged condition (Scenario 14).

\subsection{Load Type}


A designer may calculate the residual ultimate strength of a damaged ship structure under a vertical bending moment alone with reasonable certainty. However, it is known that the horizontal bending moment may approach the magnitude of the vertical bending moment when the ship is in an oblique condition. Such a combination of horizontal and vertical loading may lead to a dangerous situation for the structure of the damaged ship. The proposed method is applied to evaluate the risk of hull collapse of the hypothetical ship under vertical bending only and under a combination of vertical and horizontal bending moments.

The sign conventions used in this study are shown in Figure 6. When the target ship is under combined vertical and horizontal bending moments, hogging results from vertical bending with a compressed starboard side (i.e. the central bulkhead moves in the starboard direction), while sagging results from vertical bending with a tensioned starboard side (i.e. the central bulkhead moves in the port direction).

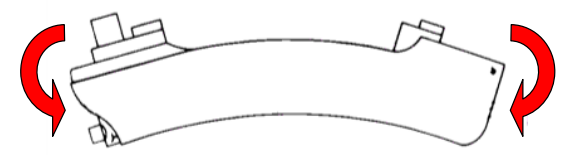

Hogging, $M_{V}(+)$

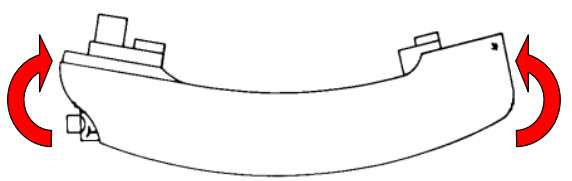

Sagging, $M_{V}(-)$

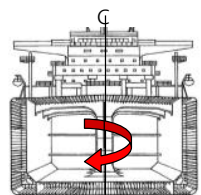

Compression at

Starboard, $\mathbf{M}_{\mathbf{H}}(+)$

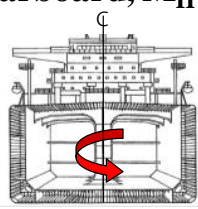

Tension at

Starboard, $\mathbf{M}_{\mathbf{H}}(-)$

Fig. 6 Sign conventions.

\subsubsection{Vertical Bending Loads}

Using the ALPS/HULL program, the ultimate longitudinal strength for both the intact and the damaged crosssections in individual scenarios is analysed in the hogging and sagging directions. Figures 7 and 8 show samples of the analysis results in terms of von Mises stress distributions at the ultimate limit state for intact and damaged crosssections, respectively, under a pure hogging vertical bending moment. Figures 9 and 10 show the corresponding results for a pure sagging vertical bending moment. The moment-curvature curves for the target structure in intact and damaged scenarios (cases of major and minor damage) are shown in Figure 11. 


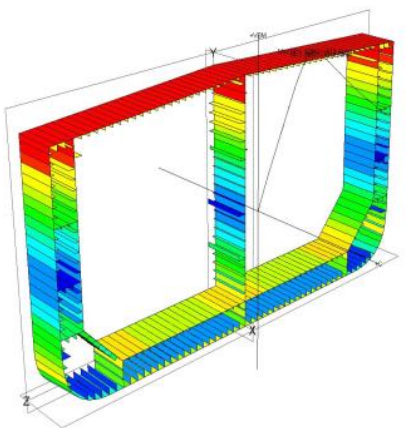

a) Scenario 3
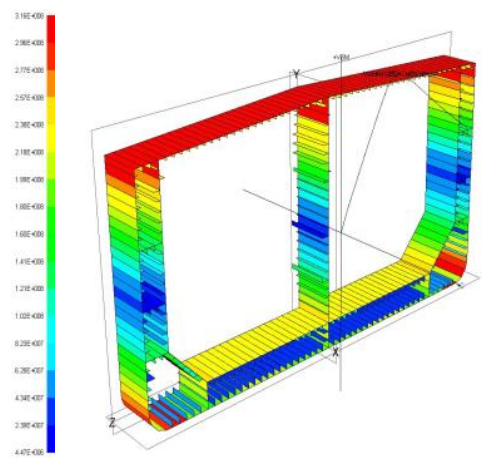

b) Scenario 16
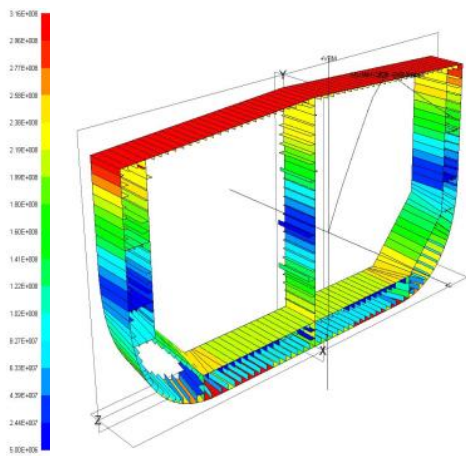

c) Scenario 26

Fig. 7 Samples of ALPS/HULL ultimate longitudinal strength calculation results in terms of von Mises stress distributions for intact cross-sections under a hogging vertical bending moment.

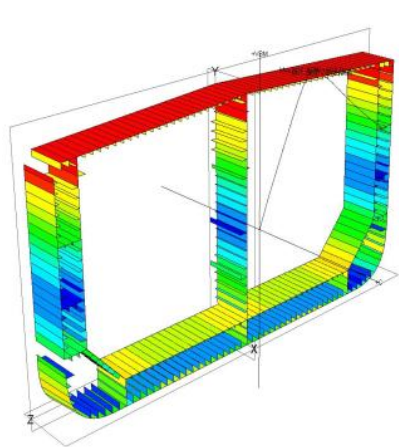

a) Scenario 3
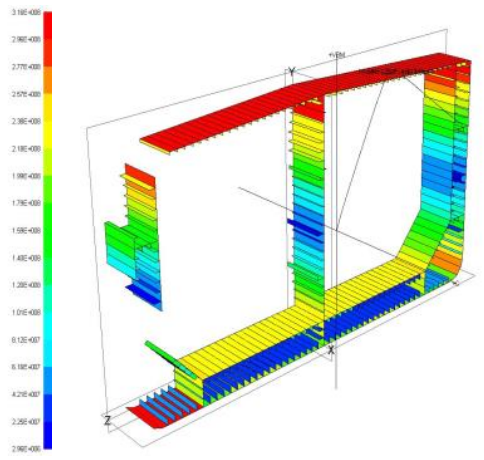

b) Scenario 16
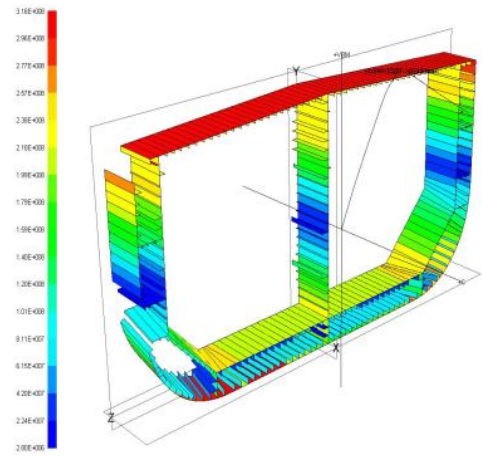

c) Scenario 26

Fig. 8 Samples of ALPS/HULL ultimate longitudinal strength calculation results in terms of von Mises stress distributions for damaged cross-sections under a hogging vertical bending moment.

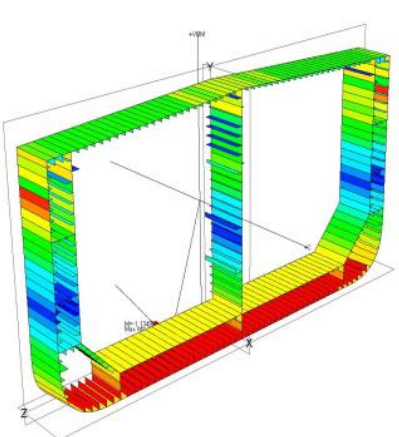

a) Scenario 3
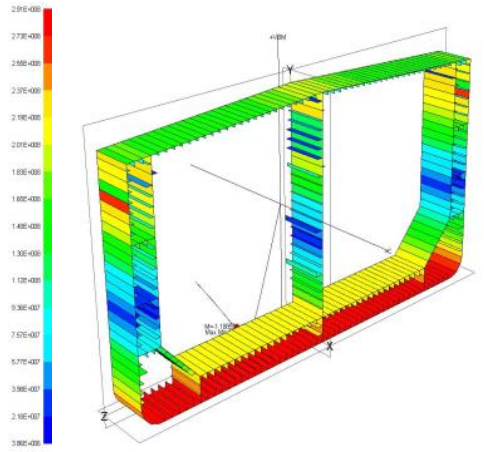

b) Scenario 16
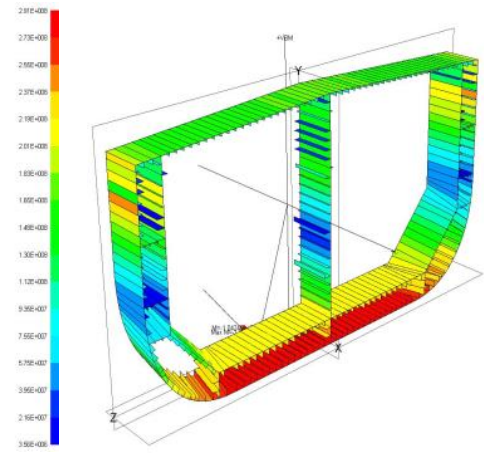

c) Scenario 26

Fig. 9 Samples of ALPS/HULL ultimate longitudinal strength calculation results in terms of von Mises stress distributions for intact cross-sections under a sagging vertical bending moment. 


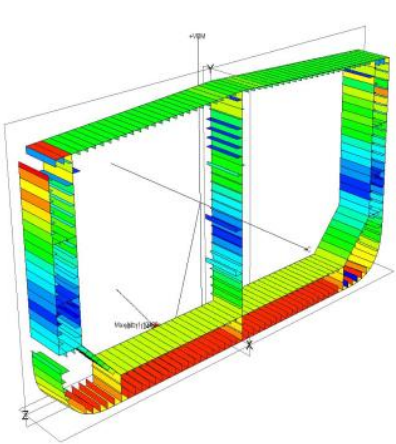

a) Scenario 3
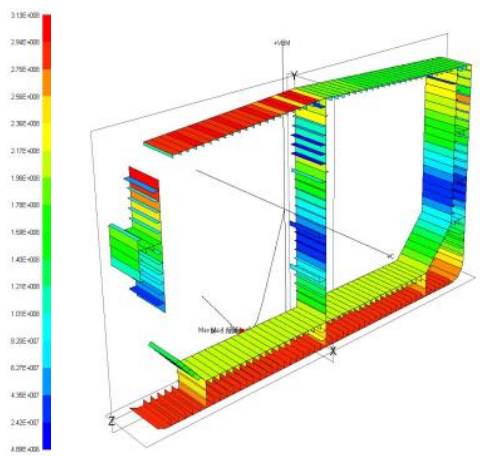

b) Scenario 16
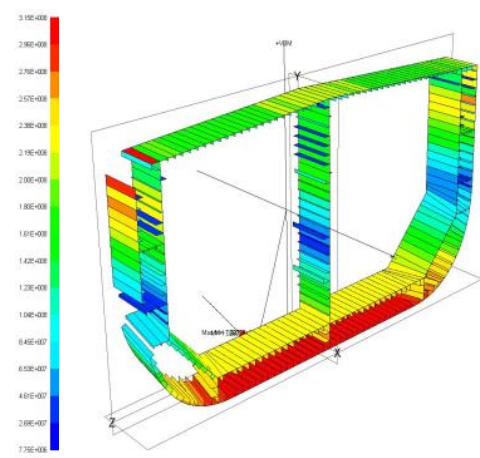

c) Scenario 26

Fig. 10 Samples of ALPS/HULL ultimate longitudinal strength calculation results in terms of von Mises stress distributions for damaged cross-sections under a sagging vertical bending moment.

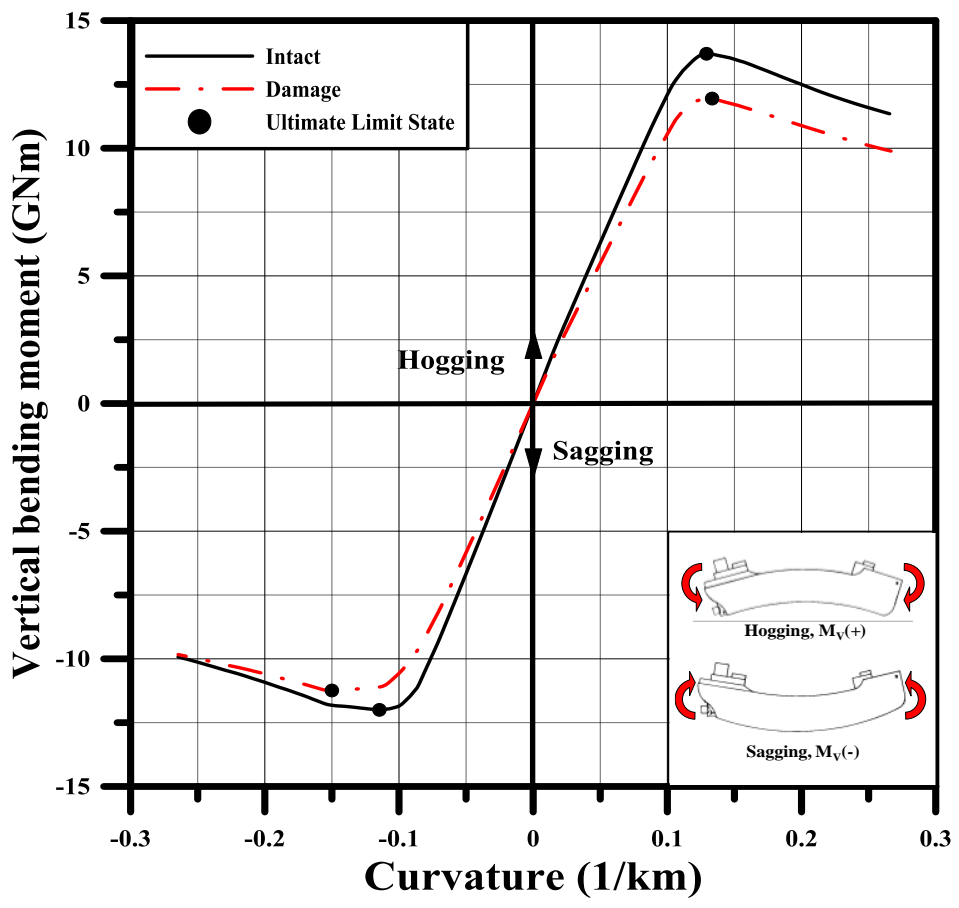

a) Major damage 


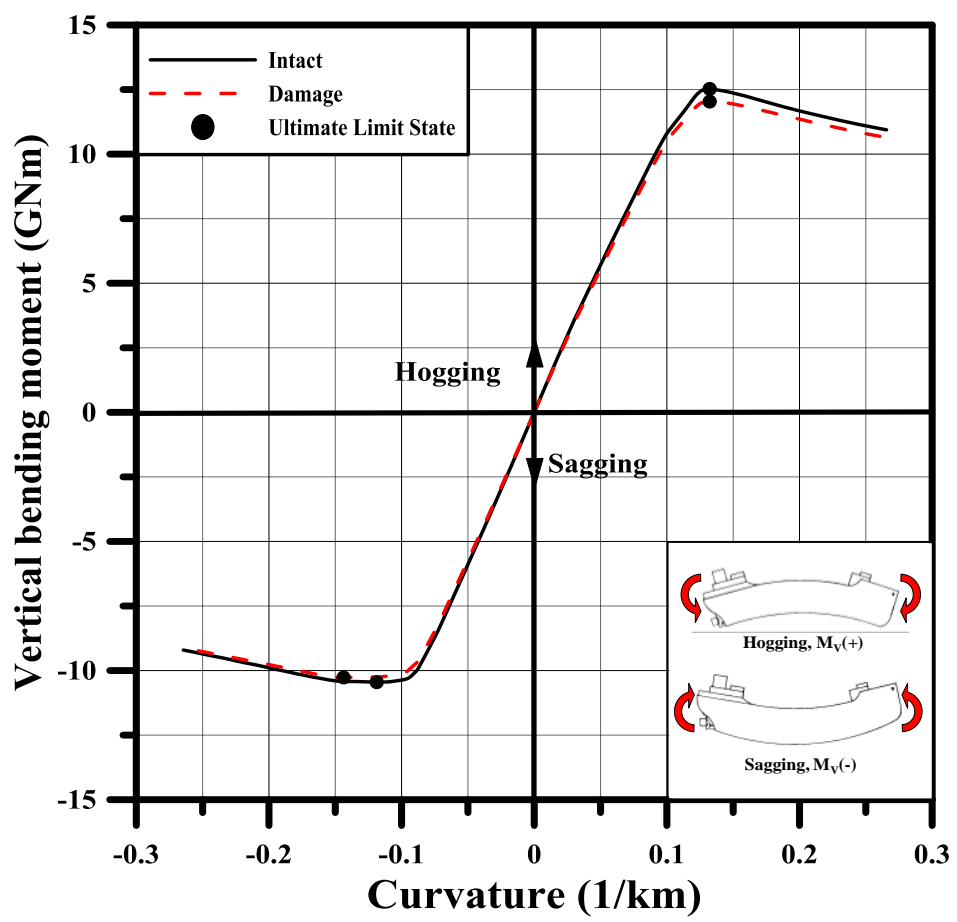

b) Minor damage

Fig. 11 The moment-curvature relationships for intact and damage scenarios under a pure vertical bending moment.

As shown in Figure 11, in the case of major damage the residual strength is significantly lower than with minor damage, which is expected because the residual ultimate longitudinal strength decreases as the extent of damage increases.

At the ultimate limit state, the curvature of the intact hull section under vertical bending is observed to be smaller (e.g. $8.1 \%$ for scenario 14) for sagging than for hogging, which is expected because the strength of the lower structure is greater than that of the deck structure.

Based on the above results, Equation (1) is then used to calculate the residual ultimate strength of the hull crosssections under a pure vertical bending moment $\left(\mathrm{RSI}_{\mathrm{V}}\right)$ for individual collision scenarios.

Based on the collision frequency calculations, an exceedance probability analysis is performed. Exceedance diagrams are then generated to represent the relationship between the exceedance probability of collision and the RSI, taking the hogging and sagging load directions into consideration, as shown in Figure 12. 


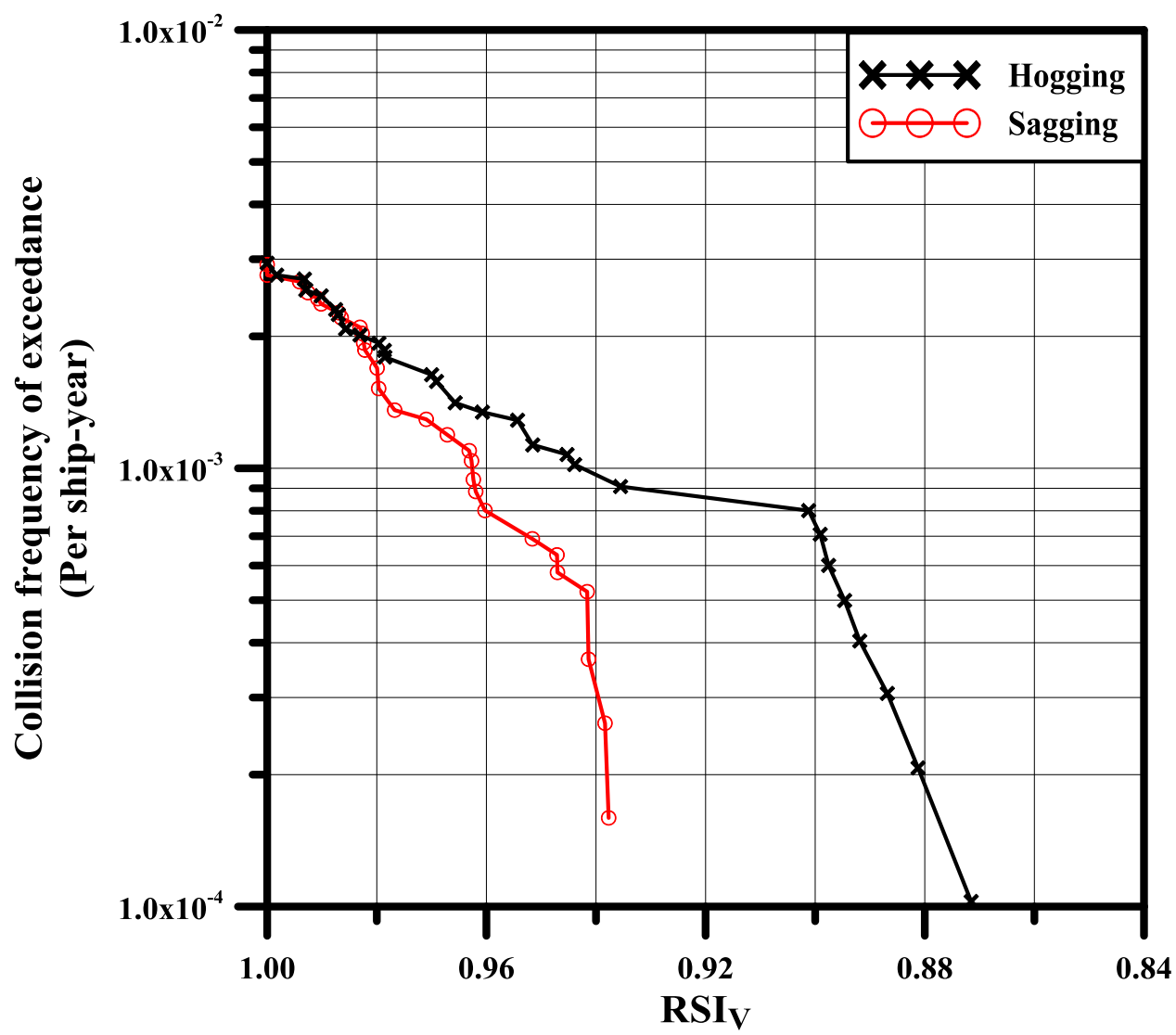

Fig. 12 Exceedance diagram for exceedance of collision frequency versus RSIv.

[Please change the $y$-axis label to read 'Collision frequency exceedance (per ship-year)'.]

\section{The use of exceedance diagrams}

- In terms of accidental limit state (ALS) design, exceedance diagrams such as that shown in Figure 12 can be used to approximately determine the minimum residual strength (i.e. the upper limit of the RSI) required at an acceptable level of risk. For example, if a designer decides to use an exceedance probability of collision value of 0.001 per ship-year as the maximum tolerable risk (i.e. the acceptance criterion), the RSIV should be no smaller than 0.9625 and 0.9425 for the sagging and hogging conditions, respectively (see Figure 12). Within a collision risk-based design (RBD) framework, these types of exceedance diagram may be useful for ensuring that the residual strength will remain within an acceptable range following damage (see Figure 13).

- These exceedance diagrams may also be useful for assessing the structural safety in terms of ship hull collapse immediately after a collision, before rescue and salvage operations take place. For example, at a certain residual strength the generated exceedance diagram can be used to evaluate the current risk of the damaged hull collapsing in terms of the exceedance probability, which can be compared with acceptance 
criteria (i.e. the maximum tolerable risk) to ensure that the damaged hull will remain within an acceptable range of safety (see Figure 13).

- Moreover, the proposed method can be used to assess the condition of collision-damaged structures together with the available acceptance criteria. For example, the International Maritime Organization (IMO, 2000) has suggested that the ultimate longitudinal strength for ships damaged due to collision and grounding should be at least $90 \%$ of the ship's as-built condition (i.e. the RSI should be no smaller than 0.9). Based on the above calculations, the lowest RSIV values in the sagging and hogging directions were found to be 0.938 and 0.872 , respectively. According to the abovementioned IMO (2000) requirements, the reduction in the strength of the target ship's structure after having been subjected to a sagging bending moment is within the acceptable range. However, the RSI of the damaged hull in the hogging condition is below the acceptable range. For fully laden oil tankers, the most critical failure mode (i.e. the ultimate limit state) will occur under sagging bending moments that cause the deck structure to buckle and collapse. It can therefore be concluded that the target ship is safe in terms of a sagging vertical bending moment. This suggests that the current methods used in ship design are acceptable and reliable.

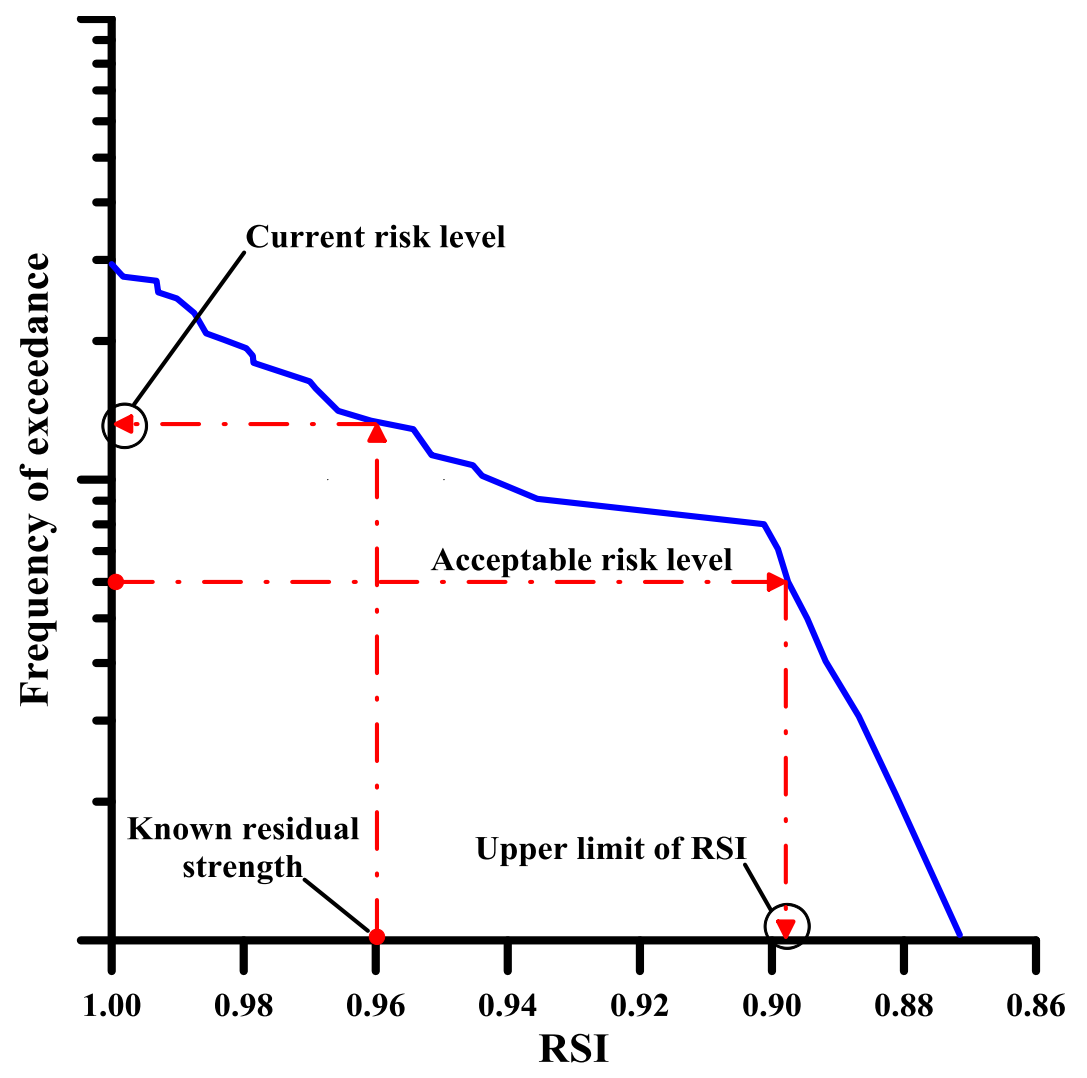

Fig. 13 Use of an exceedance diagram.

\subsubsection{Combined Vertical and Horizontal Bending Loads}


In this example, the ALPS/HULL program is used to calculate the ultimate longitudinal strength for ship hull crosssections under combined vertical and horizontal bending moments in the intact and damaged conditions for the 30 collision scenarios. Figures 14 and 15 show the results of the analysis in terms of von Mises stress distributions at the ultimate limit state of the intact and damaged cross-sections (scenario 14) under combined vertical and horizontal bending moments, in the hogging and sagging directions, respectively.

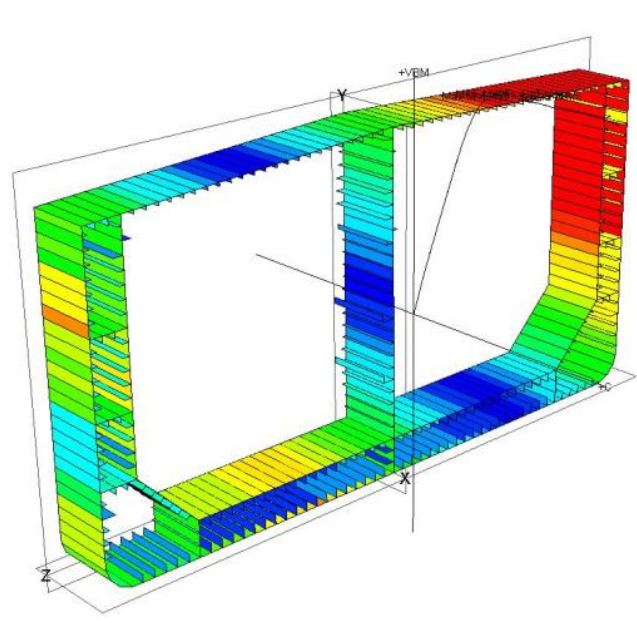

a) Intact

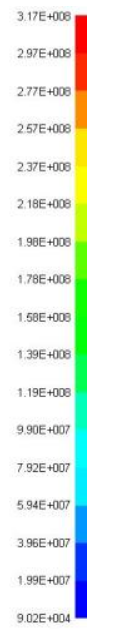

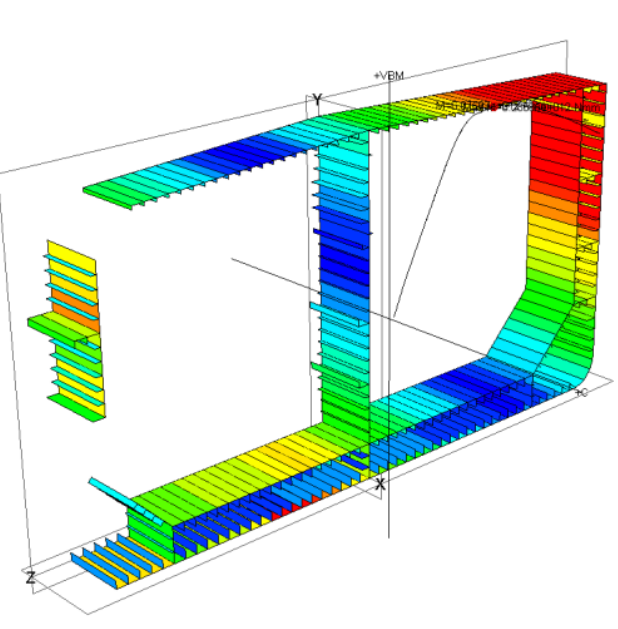

b) Damaged

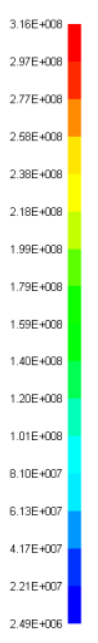

Fig. 14 ALPS/HULL ultimate longitudinal strength calculation results in terms of von Mises stress distributions for a hull cross-section under combined bending moments (hogging vertical bending with a compressed starboard side).

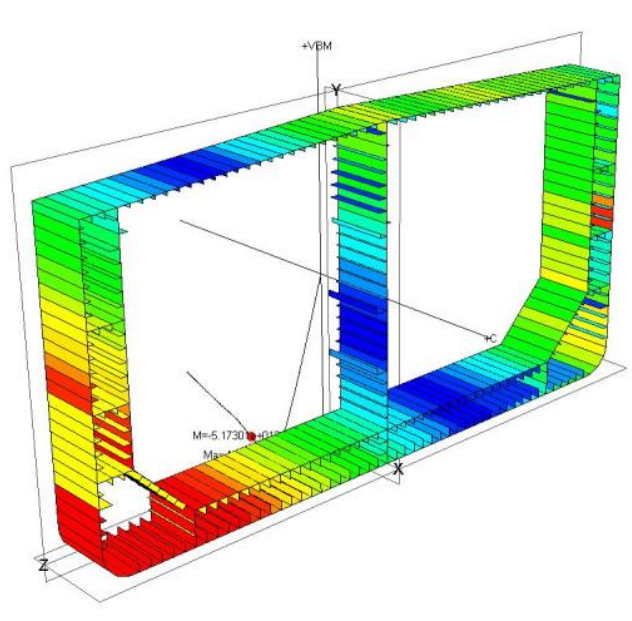

a) Intact
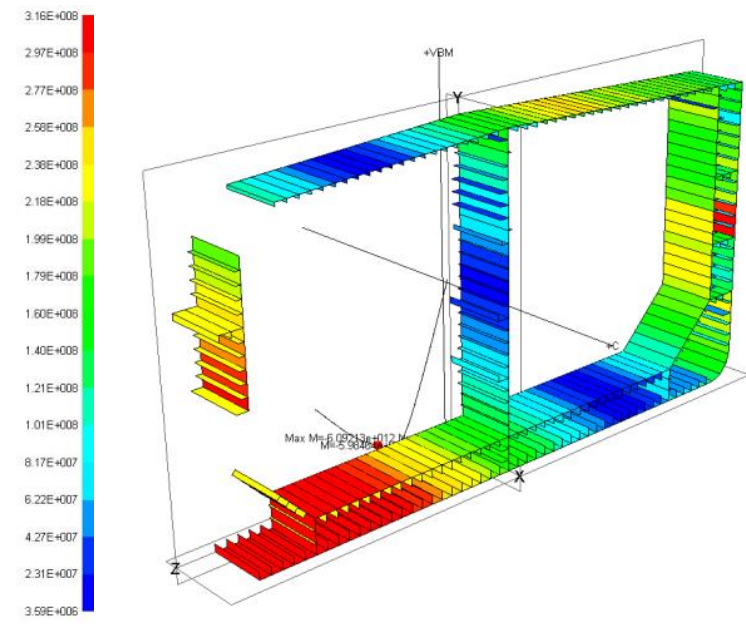

b) Damaged

Fig. 15 ALPS/HULL ultimate longitudinal strength calculation results in terms of von Mises stress distributions for a hull cross-section under combined bending moments (sagging vertical bending with a tensioned starboard side).

Based on the results obtained, the effect of combined loadings on the ultimate strength capacity is investigated by plotting interaction curves for the hull cross-sections in the intact and the damaged condition. Figure 16 shows these ultimate strength interaction curves for scenario 14 . 


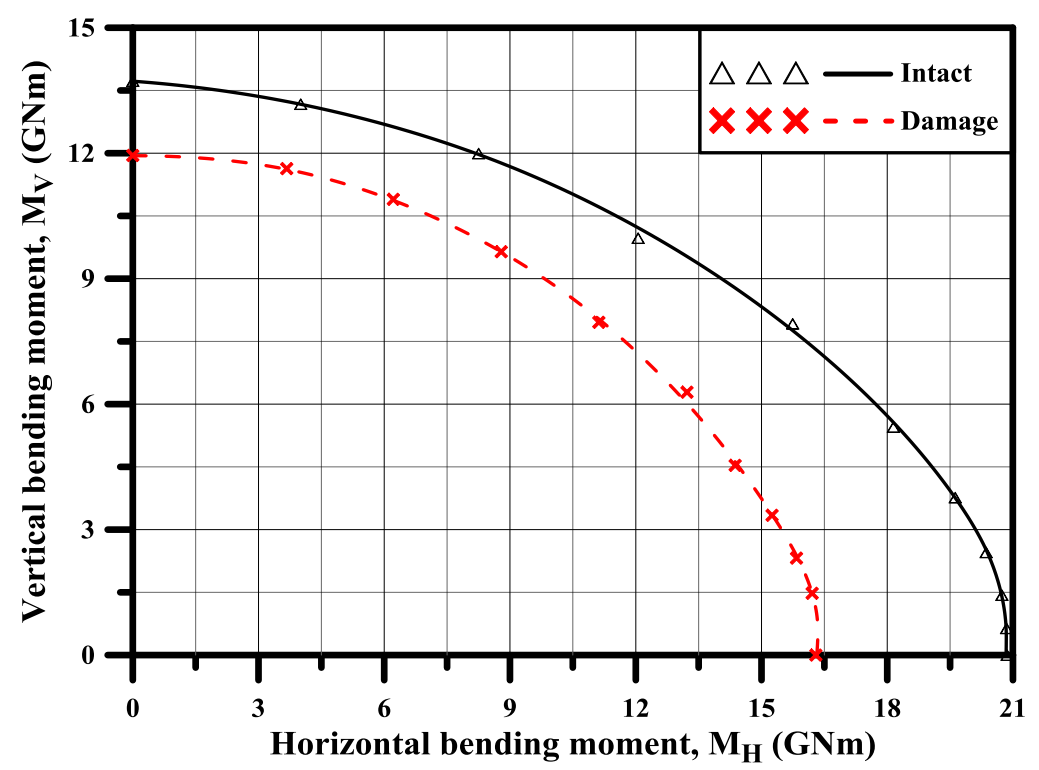

Fig. 16 Ultimate strength interaction curves.

[In the diagram, please make the $\mathrm{M}$ in $\mathrm{M}_{\mathrm{H}}$ and $\mathrm{M}_{\mathrm{V}}$ italics, i.e. $M_{\mathrm{H}}$ and $M_{\mathrm{V}}$.]

In this example, the ratio of the applied loadings is called the 'loading ratio' and is defined as the ratio of the horizontal, $M_{\mathrm{H}}$, to the vertical, $M_{\mathrm{V}}$, bending moment $\left(M_{\mathrm{H}} / M_{\mathrm{V}}\right)$. To estimate the residual strength of both intact and damaged structures under combined vertical and horizontal bending moments, loading ratios from zero (i.e. pure vertical bending) to infinity (i.e. pure horizontal bending) may be considered. However, this study focuses on that region between 0 and 1 , in intervals of 0.1 , because critical loading combinations tend to be those in which the vertical bending moment is larger than the horizontal one (i.e. the loading ratio is less than 1).

The interaction curves (see Figure 16) obtained for each intact and damaged condition are used to determine the vertical and horizontal bending moments of the $i$ th collision scenario studied at each $j$ th loading ratio. Two RSIs are developed; one for the vertical bending moment $\left(\operatorname{RSI}_{\left.\mathrm{V}_{-} i_{-}\right)}\right)$and the other for the horizontal bending moment $\left(\mathrm{RSI}_{H_{-} i j}\right)$, as shown in Equations (2) and (3) respectively:

$$
\begin{gathered}
\mathrm{RSI}_{\mathrm{V}_{-} i_{-} j}=\frac{M_{\mathrm{D} \_\mathrm{V}}}{M_{\mathrm{I}_{-} \mathrm{V}}} \\
\mathrm{RSI}_{\mathrm{H}_{-} i_{-} j}=\frac{M_{\mathrm{D} \_\mathrm{H}}}{M_{\mathrm{I} \_\mathrm{H}}}
\end{gathered}
$$

where $M_{\mathrm{I}_{-} \mathrm{v}}$ and $M_{\mathrm{D}_{-} \mathrm{v}}$ are the vertical bending moments for intact and damaged cross-sections, respectively, and $M_{\mathrm{I}_{\_} \mathrm{H}}$ and $M_{\mathrm{D} \_\mathrm{H}}$ are the corresponding horizontal bending moments.

Based on the results obtained, exceedance diagrams representing exceedance of collision frequency versus RSIV and $\mathrm{RSI}_{\mathrm{H}}$ were then individually generated for each of the assumed loading ratios. Figures 17 and 18 show samples of 
such exceedance diagrams generated at a loading ratio of 0.2. In these diagrams, hogging means vertical bending with a compressed starboard side and sagging means vertical bending with a tensioned starboard side (see Figure 6).

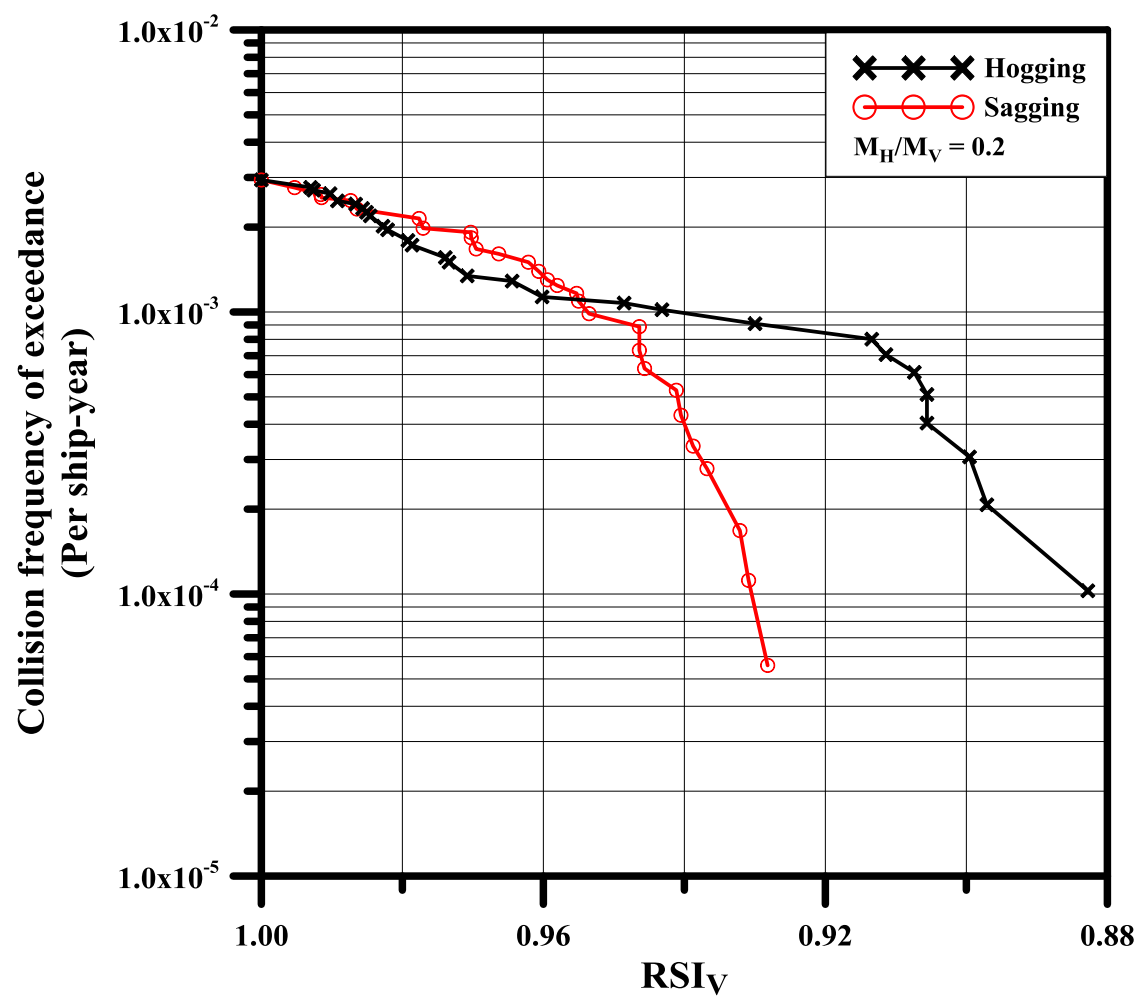

Fig. 17 Exceedance diagram for exceedance of collision frequency versus $\mathrm{RSI}_{\mathrm{V}}$ at a loading ratio of 0.2 .

[Please change the $y$-axis label to read 'Collision frequency exceedance (per ship-year)'. Please also change ' $\mathrm{M}_{\mathrm{H}} / \mathrm{Mv}_{\mathrm{V}}$ ' to ' $M_{\mathrm{H}} / M_{\mathrm{V}}$ '.] 


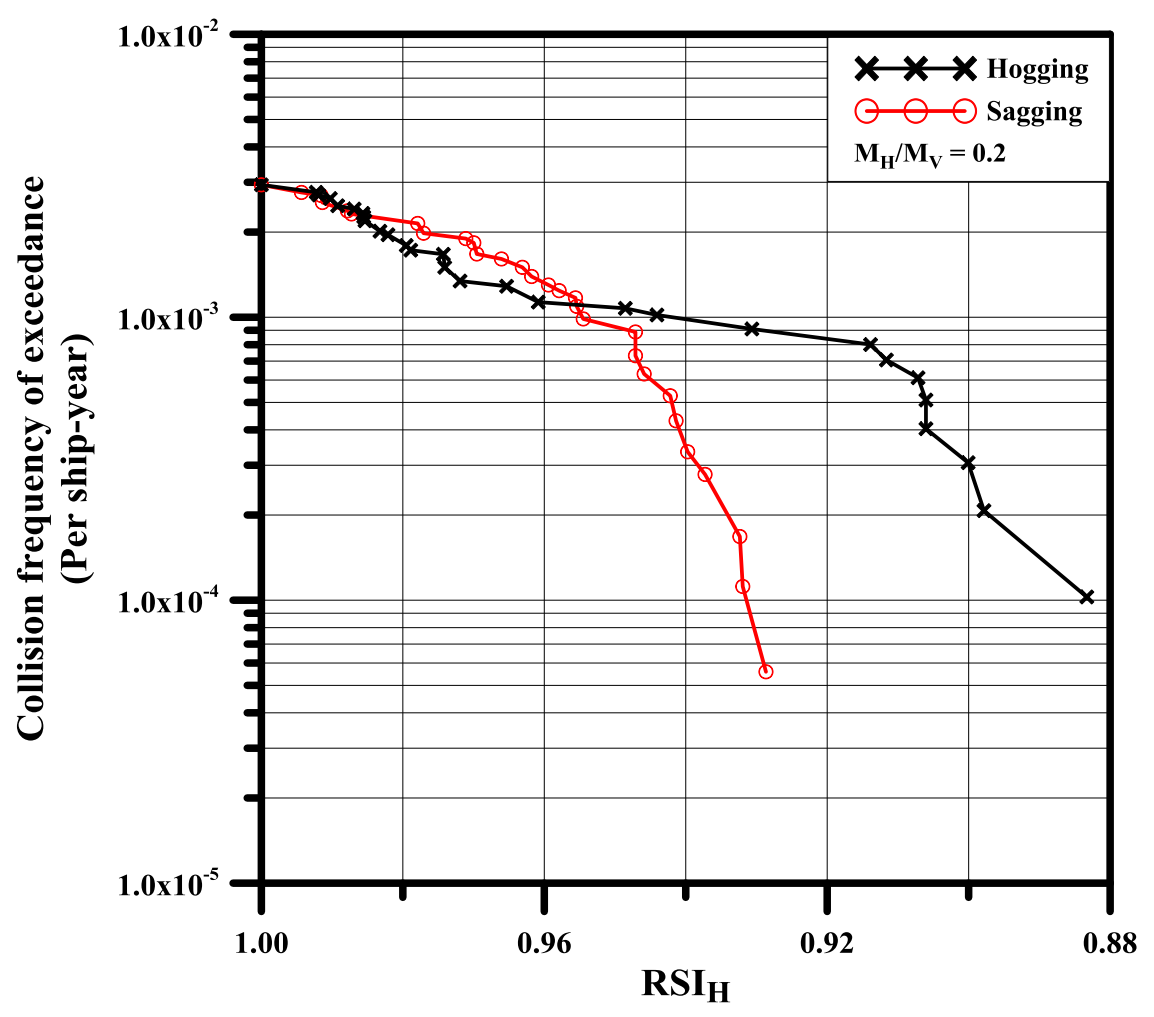

Fig. 18 Exceedance diagram for exceedance of collision frequency versus $\mathrm{RSI}_{\mathrm{H}}$ at a loading ratio of 0.2 .

[Please change the $y$-axis label to read 'Collision frequency exceedance (per ship-year)'. Please also change ' $\mathrm{M}_{\mathrm{H}} / \mathrm{M}_{\mathrm{V}}$ ' to ' $M_{\mathrm{H}} / M_{\mathrm{V}}$ '.]

At a particular exceedance probability of collision, the RSIs for the vertical and horizontal bending moments can be obtained at each loading ratio. In this study, the values 0.001 and 0.0001 per ship-year are taken to be the collision exceedance probabilities (i.e. the maximum tolerable risk). The exceedance diagrams are then used to determine the corresponding $\mathrm{RSI}_{\mathrm{V}}$ and $\mathrm{RSI}_{\mathrm{H}}$ values at these exceedance levels at each loading ratio $\left(M_{\mathrm{H}} / M_{\mathrm{V}}\right)$.

Based on the results obtained, the relationship between the calculated RSIs and the loading ratio $\left(M_{\mathrm{H}} / M_{\mathrm{V}}\right)$ are established in the form of an 'R-L diagram'. Two diagrams, for the vertical and the horizontal bending moments respectively, are developed at each exceedance level. Figures 19 and 20 show the R-L diagrams at an exceedance level of 0.001 per ship-year for the target Suezmax-class double-hull oil tanker, in which the loading ratio $\left(M_{\mathrm{H}} / M_{\mathrm{V}}\right)$ is plotted against $\mathrm{RSI}_{\mathrm{V}}$ and $\mathrm{RSI}_{\mathrm{H}}$, respectively. Figures 21 and 22 show the corresponding $\mathrm{R}-\mathrm{L}$ diagrams at an exceedance level of 0.0001 per ship-year. 


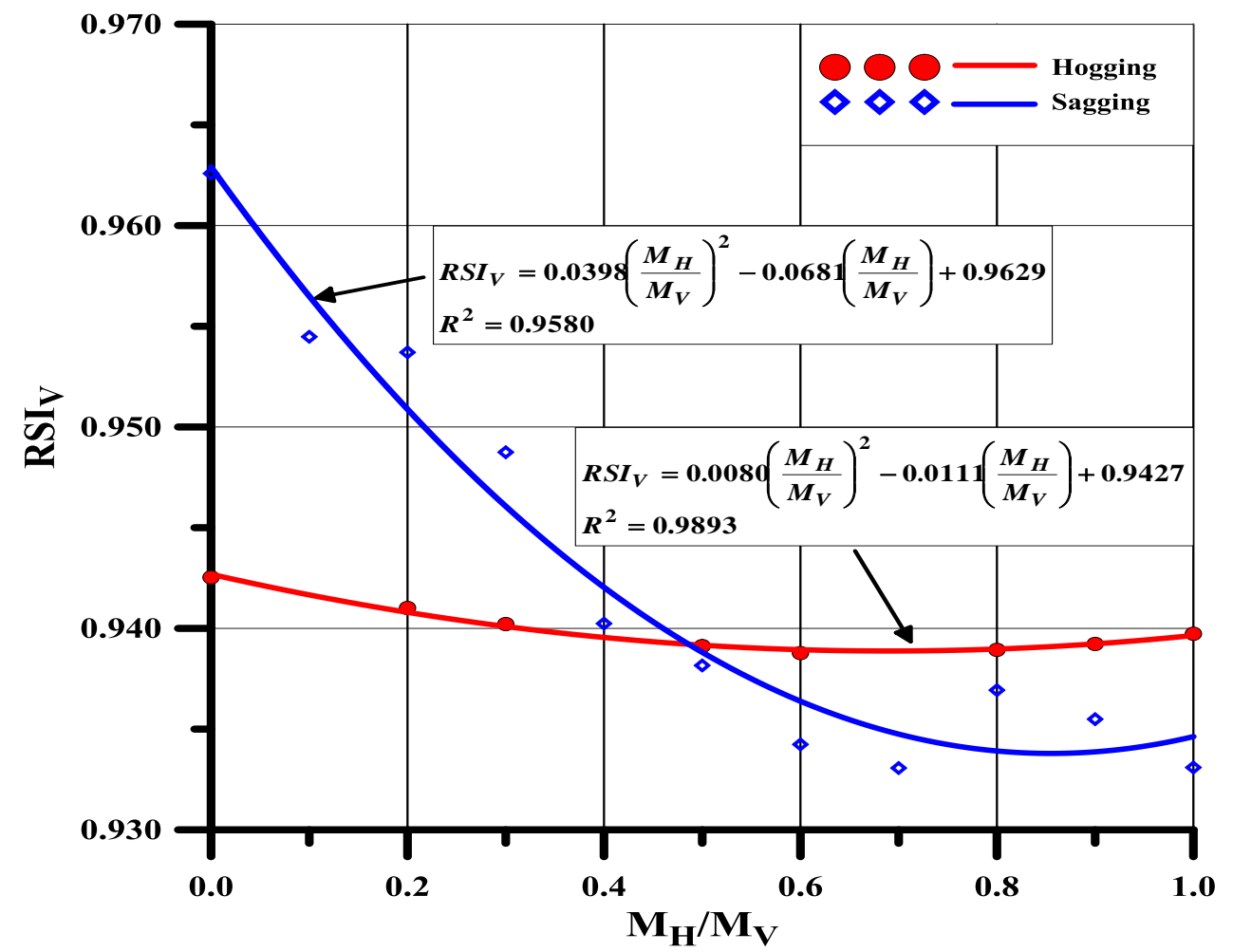

Fig. $19 \mathrm{R}-\mathrm{L}$ diagram for the target Suezmax-class double-hull oil tanker: RSIV versus loading ratio $\left(M_{\mathrm{H}} / M_{\mathrm{V}}\right)$ at an exceedance probability of collision of 0.001 per ship-year.

[Please change the $x$-axis label to read ' $M_{\mathrm{H}} / M_{\mathrm{V}}$ ', and change the equations to read 'RSII', ' $M_{\mathrm{H}}$ ' and ' $M_{\mathrm{V}}$ '.] 


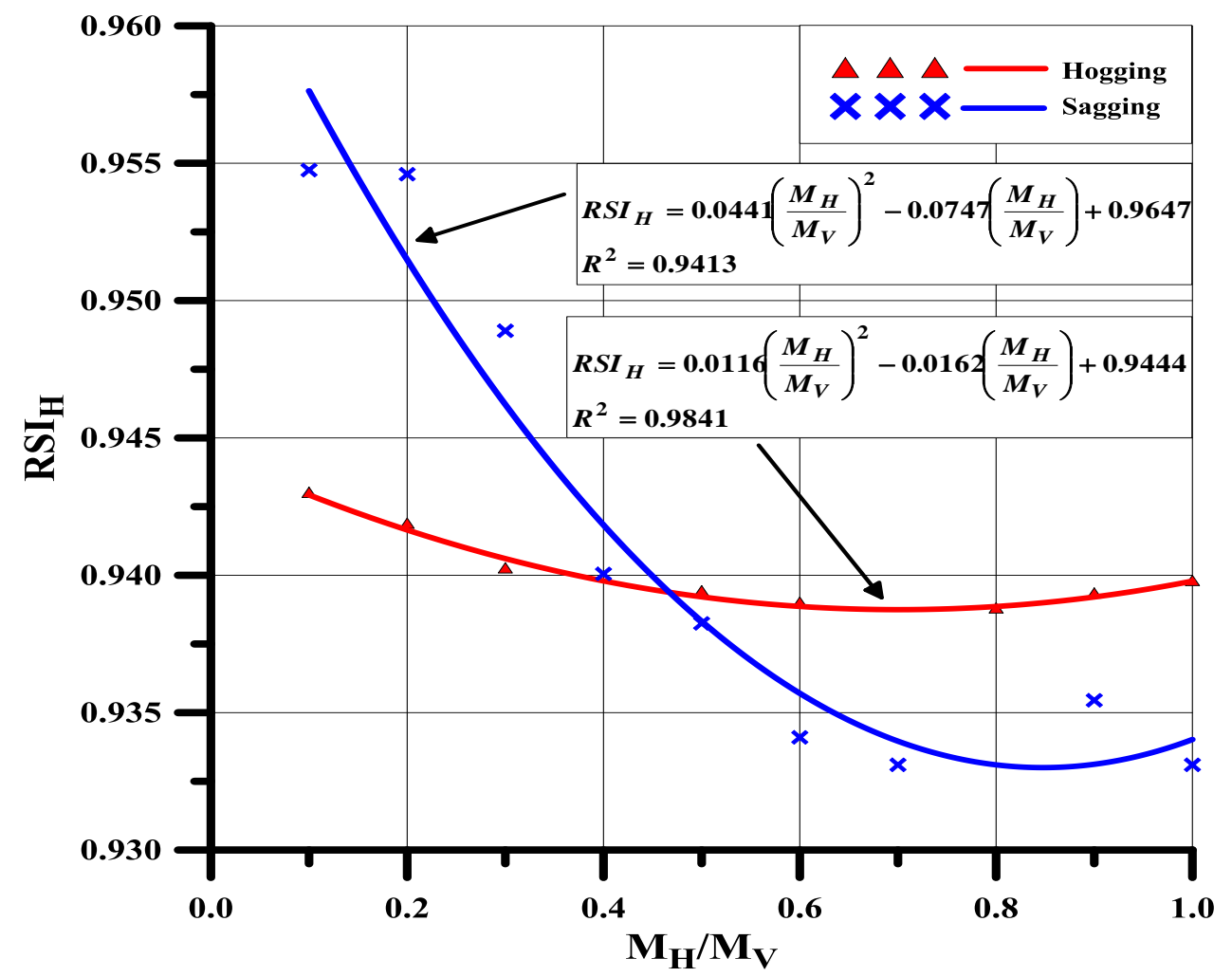

Fig. $20 \mathrm{R}-\mathrm{L}$ diagram for the target Suezmax-class double-hull oil tanker: $\mathrm{RSI}_{\mathrm{H}}$ versus loading ratio $\left(M_{\mathrm{H}} / M_{\mathrm{V}}\right)$ at an exceedance probability of collision of 0.001 per ship-year.

[Please change the $x$-axis label to read ' $M_{\mathrm{H}} / M_{\mathrm{V}}$ ', and change the equations to read 'RSI ${ }_{\mathrm{H}}$ ', ' $M_{\mathrm{H}}$ ' and ' $M_{\mathrm{V}}$ '.] 


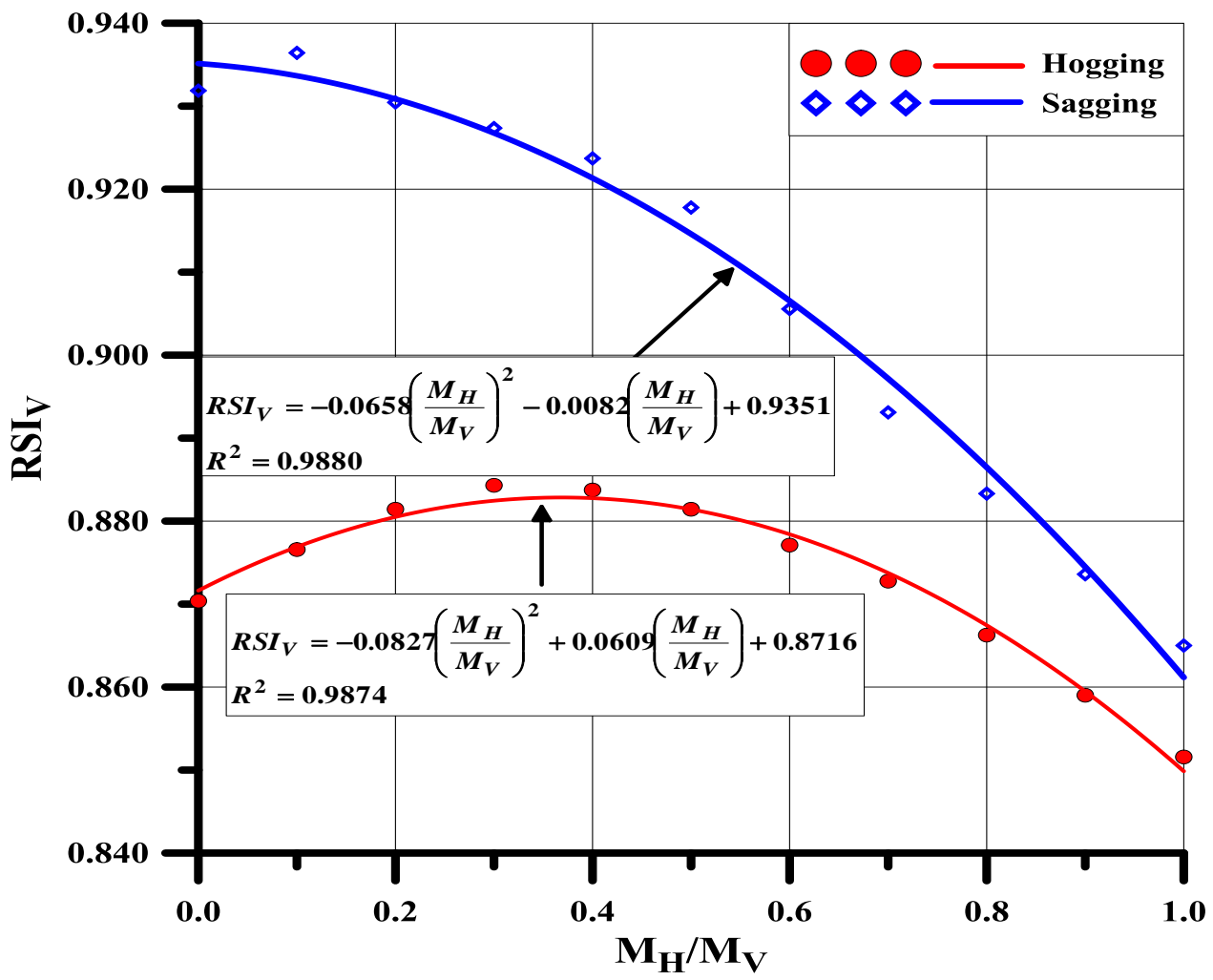

Fig. $21 \mathrm{R}-\mathrm{L}$ diagram for the target Suezmax-class double-hull oil tanker: RSIV versus loading ratio $\left(M_{\mathrm{H}} / M_{\mathrm{V}}\right)$ at an exceedance probability of collision of 0.0001 per ship-year.

[Please change the $x$-axis label to read ' $M_{\mathrm{H}} / M_{\mathrm{V}}$ ', and change the equations to read 'RSII', ' $M_{\mathrm{H}}$ ' and ' $M_{\mathrm{V}}$ '.] 


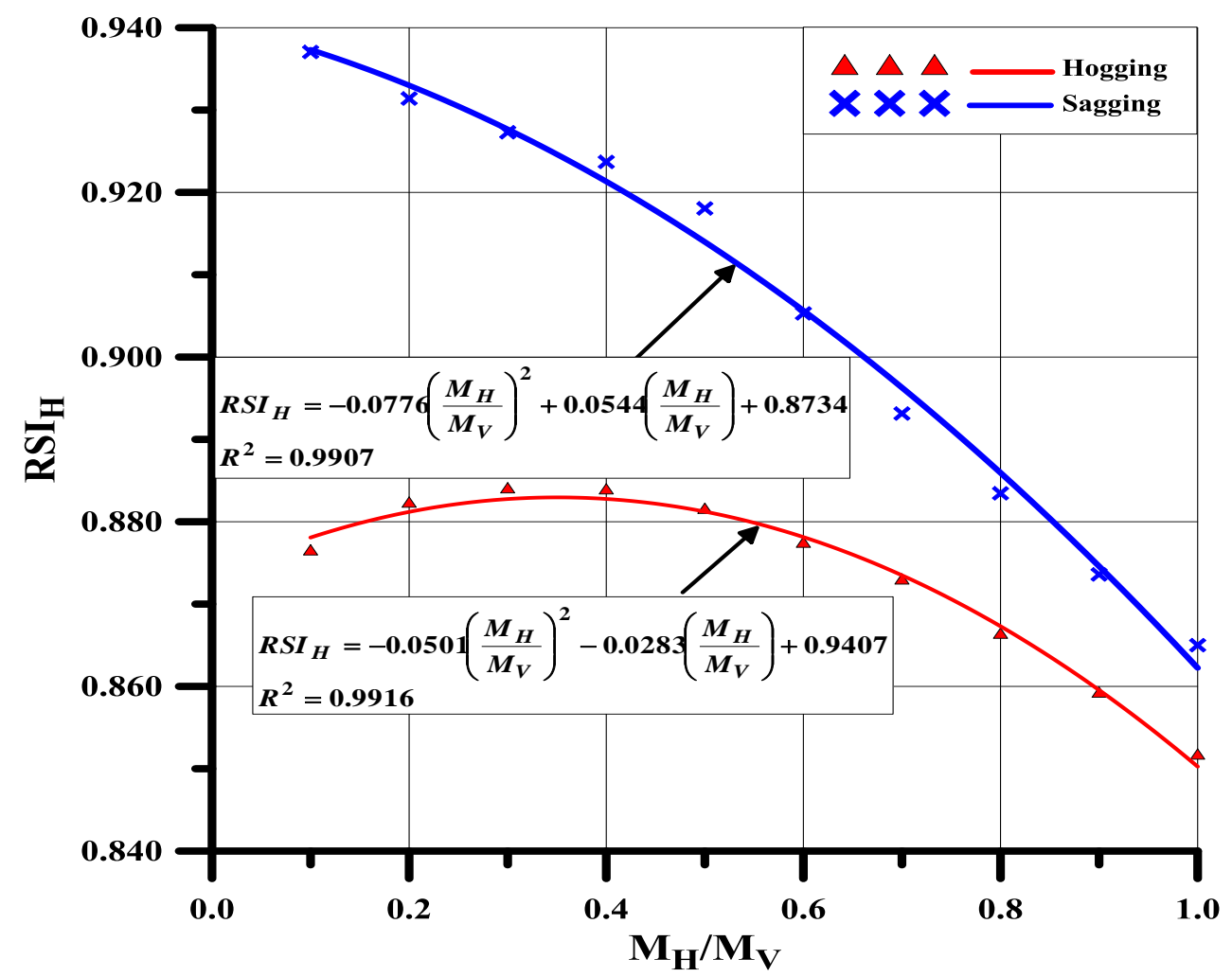

Fig. $22 \mathrm{R}-\mathrm{L}$ diagram for the target Suezmax-class double-hull oil tanker: $\mathrm{RSI}_{\mathrm{H}}$ versus loading ratio $\left(M_{\mathrm{H}} / M_{\mathrm{V}}\right)$ at an exceedance probability of collision of 0.0001 per ship-year.

[Please change the $x$-axis label to read ' $M_{\mathrm{H}} / M_{\mathrm{V}}$ ', and change the equations to read 'RSI ${ }_{\mathrm{H}}$ ', ' $M_{\mathrm{H}}$ ' and ' $M_{\mathrm{V}}$ '.]

For practical purposes, the diagrams can be empirically formulated to define RSI as a function of the loading ratio $\left(M_{\mathrm{H}} / M_{\mathrm{V}}\right)$, as follows.

\section{$\underline{\text { RSI }_{v} \text { at an exceedance probability of collision of } 0.001 \text { per ship-year: }}$}

$$
\begin{array}{lrl}
R S I_{V}=0.0080\left(\frac{M_{H}}{M_{V}}\right)^{2}-0.0111\left(\frac{M_{H}}{M_{V}}\right)+0.9427 ; & {\left[0 \leq\left(\frac{M_{H}}{M_{V}}\right) \leq 1.0\right]} \\
R S I_{V}=0.0398\left(\frac{M_{H}}{M_{V}}\right)^{2}-0.0681\left(\frac{M_{H}}{M_{V}}\right)+0.9629 ; & \text { in a hogging condition (4) } \\
& {\left[0 \leq\left(\frac{M_{H}}{M_{V}}\right) \leq 1.0\right]}
\end{array}
$$


$\underline{\text { RSI }_{H} \text { at an exceedance probability of collision of } 0.001 \text { per ship-year: }}$

$$
\begin{array}{lll}
R S I_{H}=0.0116\left(\frac{M_{H}}{M_{V}}\right)^{2}-0.0162\left(\frac{M_{H}}{M_{V}}\right)+0.9444 ; & & {\left[0.1 \leq\left(\frac{M_{H}}{M_{V}}\right) \leq 1.0\right]} \\
R S I_{H}=0.0441\left(\frac{M_{H}}{M_{V}}\right)^{2}-0.0747\left(\frac{M_{H}}{M_{V}}\right)+0.9647 ; & \text { in a hogging condition (6) } \\
& {\left[0.1 \leq\left(\frac{M_{H}}{M_{V}}\right) \leq 1.0\right]}
\end{array}
$$

in a sagging condition (7)

$\underline{\text { RSI }} v$ at an exceedance probability of collision of 0.0001 per ship-year:

$$
R S I_{V}=-0.0827\left(\frac{M_{H}}{M_{V}}\right)^{2}+0.0609\left(\frac{M_{H}}{M_{V}}\right)+0.8716 ; \quad\left[0 \leq\left(\frac{M_{H}}{M_{V}}\right) \leq 1.0\right]
$$

in a hogging condition (8)

$$
R S I_{V}=-0.0658\left(\frac{M_{H}}{M_{V}}\right)^{2}-0.0082\left(\frac{M_{H}}{M_{V}}\right)+0.9351 ; \quad\left[0 \leq\left(\frac{M_{H}}{M_{V}}\right) \leq 1.0\right]
$$

in a sagging condition (9)

$\underline{\text { RSI }_{H}}$ at an exceedance probability of collision of 0.0001 per ship-year:

$$
R S I_{H}=-0.0501\left(\frac{M_{H}}{M_{V}}\right)^{2}-0.0283\left(\frac{M_{H}}{M_{V}}\right)+0.9407 ; \quad\left[0.1 \leq\left(\frac{M_{H}}{M_{V}}\right) \leq 1.0\right]
$$

in a hogging condition (10)

$$
R S I_{H}=-0.0776\left(\frac{M_{H}}{M_{V}}\right)^{2}+0.0544\left(\frac{M_{H}}{M_{V}}\right)+0.8734
$$

$$
\left[0.1 \leq\left(\frac{M_{H}}{M_{V}}\right) \leq 1.0\right]
$$




\section{$\underline{\text { The use of } R-L \text { diagrams }}$}

- These types of diagram will be very useful in the early stages of the design process for identifying the level of safety for ship structures that may be damaged by collision. Designers will be able to ascertain the RSI at a particular ratio of horizontal to vertical bending moment $\left(M_{\mathrm{H}} / M_{\mathrm{V}}\right)$ (see Figure 23), which can represent the strength performance of a ship that has sustained collision damage.

- Together with acceptance criteria for the residual strength performance of ship structures subjected to collision damage, these diagrams can also be used to approximately determine the allowable ratio of combined horizontal and vertical bending loads (i.e. the combination ratio of the design loads) (see Figure 23).

- Taking the IMO, (2000) requirements into consideration, such diagrams can be used to determine the upper limit of the horizontal to vertical bending ratio $\left(M_{\mathrm{H}} / M_{\mathrm{V}}\right)$ corresponding to, for example, $90 \%$ of the ultimate longitudinal strength in an intact condition at an exceedance probability of collision of 0.0001 per ship-year. According to Figures 21 and 22, the upper limits of the horizontal to vertical bending ratio $\left(M_{\mathrm{H}} / M_{\mathrm{V}}\right)$ in the sagging condition are 0.6715 and 0.6618 for $\mathrm{RSI}_{\mathrm{V}}$ and $\mathrm{RSI}_{\mathrm{H}}$, respectively.

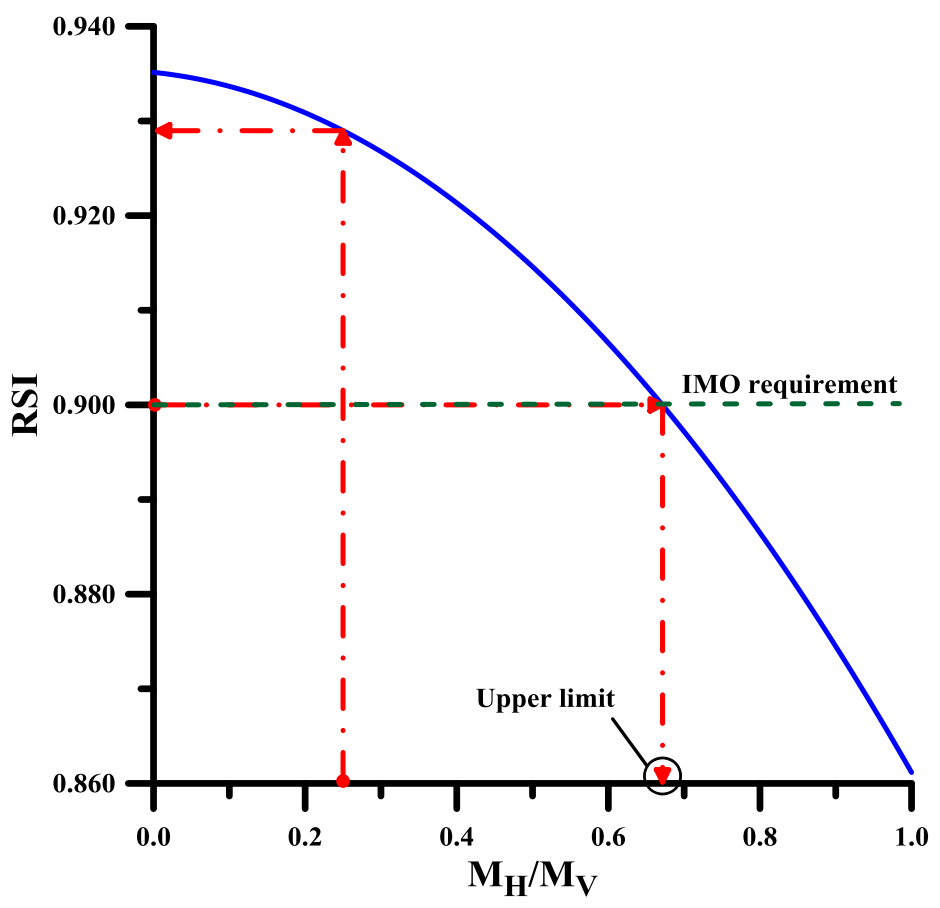

Fig. 23 Use of an R-L diagram.

[Please change the $x$-axis label to read ' $M_{\mathrm{H}} / M_{\mathrm{v}}$ '.]

\section{Concluding Remarks}


Thus study has proposed an innovative method for assessing the risk of ship hull collapse following collision damage through using an efficient probabilistic approach. Following probabilistic methods developed in previous studies, 30 ship-ship collision scenarios that might represent all possible cases were selected for use in this study. Collision probability analysis was carried out to calculate the collision frequency for each scenario selected. Collision numerical analysis was performed to take account of the effects of the surrounding water and the ship's motion during and after a collision.

This method was applied to a hypothetical Suezmax-class double-hull oil tanker to demonstrate its applicability through two applied examples. In the first example, the residual strength of the target ship structure was examined under a pure vertical bending moment only. A probabilistic approach was then applied in carrying out an exceedance probability analysis, generating exceedance diagrams representing the exceedance probability of collision versus the residual strength index (RSI).

In the second example, the residual strength of the target ship structure was investigated for each damage scenario under a combination of vertical and horizontal bending loads. Residual strength indices were subsequently calculated at various loading ratios $\left(M_{\mathrm{H}} / M_{\mathrm{V}}\right)$. The relationships between the exceedance probability of collision and the RSI were then individually established for each loading ratio.

Using the exceedance diagrams generated in the second example, the RSI was then calculated for individual loading ratios at a particular exceedance probability of collision (i.e. the maximum tolerable risk). The results were then formulated in terms of the RSI and the loading ratio to produce R-L diagrams.

From the results obtained, the following conclusions can be drawn:

1. Considering the pure vertical bending moment only, the generated exceedance diagrams can be used to approximately determine the upper limit of the RSI, which represents the minimum residual strength required at a certain level of risk. The exceedance diagrams may also be useful for developing a collision risk-based design (RBD) framework to ensure that the strength of a damaged hull remains within an acceptable range.

2. In terms of salvage and rescue operations, these types of exceedance diagram can be used for a first-cut evaluation of the risk of a damaged hull collapsing immediately after a collision. The value obtained for the risk may then be compared with available acceptance criteria.

3. According to the requirements of the IMO (2000), application of the proposed method to the target ship's structure verified that the present hull structure has a sufficient level of safety if damaged under a vertical bending load. This suggests that the current methods used in ship design are acceptable and reliable. The proposed method may also be useful in developing a condition assessment framework for ship structures damaged by collision.

4. Considering combined vertical and horizontal bending loads, the ' $\mathrm{R}-\mathrm{L}$ diagrams' and corresponding formulations developed in the second example may also be used to characterize levels of safety for a ship that has sustained collision damage. 
5. Using the $\mathrm{R}-\mathrm{L}$ diagrams, the residual strength performance of a damaged structure at a particular exceedance probability of collision can be readily determined in terms of the RSI at a specific horizontal to vertical bending moment ratio $\left(M_{\mathrm{H}} / M_{\mathrm{V}}\right)$.

6. The $\mathrm{R}-\mathrm{L}$ diagrams could also be used to approximately determine the combination ratio of the design loads, in terms of horizontal to vertical bending ratios, for an acceptable level of longitudinal residual strength for ship structures that may sustain collision damage.

7. The proposed method is applicable to any type of ship structure.

Further studies are being carried out to establish the relationship between the ultimate longitudinal strength and the collision damage index in terms of the amount and location of the damage.

\section{Acknowledgements}

This research was undertaken at The Lloyd's Register Foundation (LRF) Research Centre of Excellence (The Korea Ship and Offshore Research Institute) at Pusan National University, Korea. It was supported by Leading Foreign Research Institute Recruitment Program through the National Research Foundation of Korea (NRF) funded by the Ministry of Science, Ict \& future Planning (MSIP) (Grant no.: 2013044761).

\section{References}

ABS (1995). Guide for assessing hull girder residual strength, American Bureau of Shipping, Houston, TX, USA.

ALPS/HULL (2012). A computer program for progressive collapse analysis of ship hulls, Advanced Technology Center, DRS DS Systems, Inc., MD, USA.

Chen, Y.K., Kutt, L.M., Piaszczyk, C.M. and Bieniek, M.P. (1983). Ultimate strength of ship structures, SNAME Transactions, Vol. 91, No. 1, pp. 149-168.

DNV (2009). Rules for classification of ships part 3, Det Norske Veritas, Oslo, Norway.

Ferry, M., Le Sourne, H. and Besnier, F. (2002). MCOL-theoretical manual, Technical Report 01-52, French Shipbuilding Research Institute, France.

Fujii, Y. and Tanaka, K. (1970). Traffic capacity, Journal of Navigation, Vol. 24, No. 4, pp. 543-552.

Hallquist, J.O. (2010). LS-DYNA 3D theory manual, Livermore Software Technology Corporation, CA, USA.

Hughes, O.F. and Paik, J.K. (2013). Ship structural analysis and design, SNAME, Washington DC, USA.

Hussein, A.W. and Soares, C.G. (2009). Reliability and residual strength of double hull tankers designed according to the new IACS common structural rules, Ocean Engineering, Vol. 36, No. 1, pp. 1446-1459.

IMO (2000). SOLAS/2 recommended longitudinal strength, MSC.108(73), Maritime Safety Committee, International Maritime Organization, London, UK.

Khan, I.A. and Das, P.K. (2008). Reliability analysis of intact and damaged ships considering combined vertical and horizontal bending moments, Ships and Offshore Structures, Vol. 3, No. 4, pp. 371-384.

Macduff, T. (1974). The probability of vessel collisions, Ocean Industry, Vol. 9, No. 9, pp. 144-148. 
Magoga, T. and Flockhart, C. (2014). Effect of weld-induced imperfections on the ultimate strength of an aluminum patrol boat determined by the ISFEM rapid assessment method, Ships and Offshore Structures, Vol.9, No.2, pp.218-235.

Ozguc, O., Das, P.K. and Barltrop, N. (2005). A comparative study on the structural integrity of single and double side skin bulk carriers under collision damage, Marine Structures, Vol. 18, No. 1, pp. 511-547.

Paik, J.K., Thayamballi, A.K. and Che, J.S. (1996). Ultimate strength of ship hulls under combined vertical bending, horizontal bending and shearing forces, Transactions SNAME, Vol. 104, No. 1, pp. 31-59.

Paik, J.K., Thayamballi, A.K. and Yang, S.H. (1998). Residual strength assessment of ships after collision and grounding, Marine Technology, Vol. 35, No. 1, pp. 38-54.

Pedersen, P.T. (1995). Collision and grounding mechanics., The Danish Society of Naval Architects and Marine Engineers, Denmark.

Pedersen, P.T. and Zhang, S. (1998). On impact mechanics in ship collisions, Marine Structures, Vol. 11, No. 1, pp. 429-449.

Qi, E. and Cui, W. (2006). Analytical method for ultimate strength calculations of intact and damaged ship hulls, Ships and Offshore Structures, Vol. 1, No. 2, pp. 153-163.

Sajdak, J.A.W. and Brown, A.J. (2005). Modelling longitudinal damage in ship collisions, SSC-437, Ship Structural Committee, Washington DC., USA.

Servis, D., Samuelides, E., Louka, T. and Voudouris, G. (2002). Implementation of finite-element codes for the simulation of ship-ship collisions, Journal of Ship Research, Vol. 46, No. 4, pp. 239-247.

Smith, C.S. (1977). Influence of local compression failure on ultimate longitudinal strength of a ship hull, Proceeding of International Symposium on Practical Design in Shipbuilding, Tokyo, Japan.

Sun, F., Pu, Y., Chan, H.S., Dow, R.S., Shahid, M. and Das, P.K. (2011). Reliability-based performance assessment of damaged ships, Report No. SSC-459, Ship Structure Committee, VA, USA.

Ueda, Y., Rashed, S.M.H. and Paik, J.K. (1984). Plates and stiffened plate units of the idealized structural unit method, Journal of the Society of Naval Architects of Japan, Vol. 156, No. 1, pp. 366-377.

Wang, G., Chen, Y., Zhang, H. and Peng, H. (2002). Longitudinal strength of ships with accidental damages, Marine Structures, Vol. 15, No. 2, pp. 119-138.

Youssef, S.A.M., Ince, S.T., Kim, Y.S., Paik, J.K., Cheng, F. and Kim, M.S. (2014a). Quantitative risk assessment for collisions involving double hull oil tankers, International Journal of Maritime Engineering, Vol. 156, Part A2, pp. 157-174.

Youssef, S.A.M., Kim, Y.S., Paik, J.K., Cheng, F. and Kim, M.S. (2014b). Hazard identification and probabilistic scenario selection for ship-ship collision accidents, International Journal of Maritime Engineering, Part A1, pp. 61-80. 